\title{
Double-stranded phosphodiester cytosine- guanine oligodeoxynucleotide complexed with calcium phosphate as a potent vaccine adjuvant for activating cellular and ThI-type humoral immunities
}

This article was published in the following Dove Press journal:

International Journal of Nanomedicine

\author{
Nobutaka Hanagata ${ }^{1,2}$ \\ Xianglan $\mathrm{Li}^{\prime}$ \\ Min-Hua Chen' \\ Jie $\mathrm{Li}^{\prime}$ \\ Shinya Hattori'
}

'Nanotechnology Innovation Station, National Institute for Materials Science, Tsukuba, ${ }^{2}$ Graduate School of Life Science, Hokkaido University, Sapporo, Japan
Correspondence: Nobutaka Hanagata Nanotechnology Innovation Station, National Institute for Materials Science, I-2-I Sengen, Tsukuba, Ibaraki 305-0047, Japan Email hanagata.nobutaka@nims.go.jp

\begin{abstract}
Conventional class B cytosine-guanine $(\mathrm{CpG})(\mathrm{CpG}-\mathrm{B})$ oligodeoxynucleotide (ODNs) consisting of a single-stranded (ss) phosphorothioate (PT) backbone (ss CpG-B-PT) is converted from a proinflammatory cytokine inducer to a type-I interferon (IFN) inducer when complexed with cationic materials. In this study, we designed ss $\mathrm{CpG}-\mathrm{B}$ and double-stranded (ds) CpG-B ODNs with a phosphodiester (PD) backbone (ss CpG-B-PD and ds CpG-B-PD, respectively) that became type-I IFN inducers upon complexation with Lipofectamine 2000 (Lipo), a cationic liposome. The ds CpG-B-PD complex induced higher IFN- $\beta$ expression in mouse macrophage-like RAW264 cells than ss CpG-B-PD and ss CpG-B-PT complexes. The fold induction of IFN- $\beta$ increased with the number of $\mathrm{CpG}$ motifs in ds CpG-B-PD, and a complex of ds CpG-B-PD consisting of 72 base pairs with nine CpG motifs (ds CpG-B72-PD) and Lipo showed the highest capacity to induce IFN- $\beta$. The materials and method used for complexation influenced the degree of IFN- $\beta$ induction: ds CpG-B72-PD entrapped by calcium phosphate (CaP) (ds CpG-B72-PD/CaP) showed a higher induction capacity than ds CpG-B72-PD adsorbed onto the $\mathrm{CaP}$ surface. Entrapment of ds $\mathrm{CpG}-\mathrm{B} 72-\mathrm{PD}$ by $\mathrm{CaP}$ also enhanced the induction of the proinflammatory cytokine interleukin-12. Vaccinating mice with ds $\mathrm{CpG}-\mathrm{B} 72-\mathrm{PD} / \mathrm{CaP}$ in conjunction with ovalbumin (OVA) increased the ratios of OVA-specific $\mathrm{CD} 8^{+} \mathrm{T}$ cells to total $\mathrm{CD}^{+} \mathrm{T}$ cells in peripheral blood and of OVA-specific IgG2a associated with helper T (Th) 1 cells to OVA-specific IgG1 associated with Th2 cells. These results indicate that ds $\mathrm{CpG}-\mathrm{B} 72-\mathrm{PD} / \mathrm{CaP}$ is an effective vaccine adjuvant that can activate both cellular and Th1-type humoral immune responses.
\end{abstract}

Keywords: $\mathrm{CpG}$ oligodeoxynucleotide, calcium phosphate, vaccine adjuvant, cellular immunity, humoral immunity

\section{Introduction}

Synthetic single-stranded (ss) oligodeoxynucleotides (ODNs) containing unmethylated cytosine-guanine $(\mathrm{CpG})$ dinucleotides have been studied as vaccine adjuvants for the prophylaxis or treatment of infectious diseases, cancers, and allergies, ${ }^{1-4}$ owing to their potential to activate humoral and/or cellular immunity. ${ }^{5,6} \mathrm{CpG}$ ODNs are recognized by endosomal Toll-like receptor (TLR) 9 and stimulate the production of proinflammatory cytokines and/or type-I interferon (IFN). In humans, TLR9 is expressed only in plasmacytoid dendritic cells (pDCs) and B cells, ${ }^{7-10}$ while in mice, it is also expressed in macrophages and myeloid DCs. ${ }^{11-13}$

CpG ODNs developed to date can be broadly divided into four classes based on differences in structure and immunostimulatory properties. Class A CpG (CpG-A) ODNs 
(also known as D-type) have a palindromic $\mathrm{CpG}$ sequence consisting of a native phosphodiester (PD) backbone at the center of the sequence and a poly-G sequence with an artificial nuclease-resistant phosphorothioate (PT) backbone at either end. ${ }^{714,15} \mathrm{CpG}-\mathrm{A}$ activates pDCs to strongly induce type-I IFN but not B cell activation. ${ }^{15,16}$ Class B CpG (CpG-B) ODNs (also known as K-type) have a linear structure consisting entirely of a PT backbone containing multiple $\mathrm{CpG}$ motifs. ${ }^{7,14,17,18}$ CpG-B triggers B cells to activate and induce interleukin (IL)-6 and pDCs to mature and induce tumor necrosis factor (TNF)- $\alpha$, while scarcely inducing type-I IFN. ${ }^{15,16,18}$ The other two classes, class $\mathrm{C} \mathrm{CpG}(\mathrm{CpG}-\mathrm{C})$ and class P CpG (CpG-P), have one and two palindromic $\mathrm{CpG}$ sequences, respectively, that consist entirely of a PT backbone, and both are known to activate $\mathrm{B}$ cells and pDCs. ${ }^{19-21}$ In addition, both $\mathrm{CpG}-\mathrm{C}$ and $\mathrm{CpG}-\mathrm{P}$ induce type-I IFN, although the latter has a higher capacity for induction.

Alum and emulsion are the preferred vaccine adjuvants for activation of humoral immunity, but new adjuvants that can induce cellular immunity have recently been used for prophylaxis or treatment of various diseases. Since type-I IFN induced by antigen-presenting cells including pDCs is involved in the activation of $\mathrm{CD} 8^{+} \mathrm{T}$ cells and helper $\mathrm{T}$ (Th) 1 cells, ${ }^{22-24} \mathrm{CpG}-\mathrm{A}$ and $\mathrm{CpG}-\mathrm{P}$ were considered as candidate vaccine adjuvants. However, these $\mathrm{CpG}$ ODNs form uncontrollable higher-order structures due to their palindromic and/or poly-G sequences, ${ }^{21,25,26}$ which precludes their clinical application. ${ }^{27}$ One way to overcome this problem is complexation of $\mathrm{CpG}-\mathrm{B}$ with other materials such as cationic peptides, polycations, and polysaccharides, ${ }^{28-32}$ because multimerization of conventional CpG-B converts it from an inducer of proinflammatory cytokines to one of type-I IFN. However, complexation can be costly and complicated; this limits the use of CpG-B complexes as an adjuvant for vaccines with high coverage such as influenza vaccine. Furthermore, adverse drug reactions associated with the artificial nuclease-resistant PT backbone of CpG-B have been reported. ${ }^{33-40}$

In this study, we demonstrate that CpG-B composed of ss native PD backbone (ss CpG-B-PD) can more potently induce IFN- $\beta$ than conventional $\mathrm{CpG}-\mathrm{B}$ with ss PT backbone (ss CpG-B-PT) when complexed with a commercially available cationic liposome, and that double-stranded (ds) CpG-B-PD is a more effective IFN- $\beta$ inducer than the ss CpG-B-PD. We also found that ds CpG-B-PD entrapped by calcium phosphate ( $\mathrm{CaP}$; low-crystalline apatite) formed from inexpensive ingredients (calcium chloride and monosodium phosphate) could induce antigen-specific $\mathrm{CD} 8^{+} \mathrm{T}$ cells and
IgG2a antibody to a degree similar to or higher than ds CpGB-PD complexed with a cationic liposome. These results highlight the potential for using ds CpG-B-PD entrapped by $\mathrm{CaP}$ as an adjuvant for high-coverage vaccines.

\section{Materials and methods ODNs}

Synthetic and fluorescein isothiocyanate (FITC)-labeled ODNs were obtained from Fasmac (Atsugi, Japan). B-form (B-) DNA was purchased from InvivoGen (San Diego, CA, USA). ds ODNs were prepared by combining an equivalent molar ratio of two synthetic ss ODNs in TES buffer $(10 \mathrm{mM}$ Tris- $\mathrm{HCl}$ [pH 8.0], $1 \mathrm{mM} \mathrm{EDTA}$, and $0.25 \mathrm{mM} \mathrm{NaCl}$ ) and incubating the mixture at $95^{\circ} \mathrm{C}$ for $10 \mathrm{~min}$ and at $30^{\circ} \mathrm{C}$ for $60 \mathrm{~min}$. The ds ODNs were separated by polyacrylamide gel electrophoresis (E-R1020L; ATTO, Tokyo, Japan) at $20 \mathrm{~mA}$ and purified by excising the band of appropriate size from the gel in TES buffer followed by concentration with an ultracentrifugal filter unit (Amicon Ultra-0.5, Ultracel-3 membrane, $3 \mathrm{kDa}$; EMD Millipore, Billerica, MA, USA). The purified product was verified by polyacrylamide gel electrophoresis (Figure S1).

\section{Preparation of ODN complexes}

Lipofectamine 2000 (Lipo; Thermo Fisher Scientific, Waltham, MA, USA) and N-[1-(2,3-dioleoyloxy)propyl]$\mathrm{N}, \mathrm{N}, \mathrm{N}$-trimethylammonium methyl-sulfate (DOTAP) (Roche Applied Science, Penzberg, Germany) were used for the complexation of ODN with cationic liposomes. ODNLipo complexes were prepared by mixing ODN and Lipo in a 1:1 (w/w) ratio in Opti-MEM I Reduced Serum Medium (Thermo Fisher Scientific). ODN-DOTAP complexes were prepared by mixing ODN and DOTAP in a $1: 6(\mathrm{w} / \mathrm{w})$ ratio in Tris-EDTA buffer.

ODN-CaP complexes were prepared by two different loading methods - namely, adsorption and entrapment. For the adsorption method, $164 \mu \mathrm{L}$ of $11 \mathrm{mmol} / \mathrm{L} \mathrm{CaCl}_{2}(\mathrm{pH}$ 9) was added dropwise to $109 \mu \mathrm{L}$ of $11 \mathrm{mmol} / \mathrm{L} \mathrm{Na}_{2} \mathrm{HPO}_{4}$ (pH 11) at $25^{\circ} \mathrm{C}$ to form $\mathrm{CaP}$, and $17.5 \mu \mathrm{g}$ of ODNs was added. After $1 \mathrm{~h}$, the complex formed by adsorption of ODN onto the $\mathrm{CaP}$ surface was collected by centrifugation at $15,000 \times \mathrm{g}$ and $4^{\circ} \mathrm{C}$ for $15 \mathrm{~min}$. To estimate adsorption efficiency, the concentration of ODN in supernatant (ie, that was not adsorbed onto the $\mathrm{CaP}$ surface) was measured with a spectrophotometer (absorption wavelength $=260 \mathrm{~nm}$ ). For the entrapment method, $17.5 \mu \mathrm{g}$ ODN was mixed with $164 \mu \mathrm{L}$ of $11 \mathrm{mmol} / \mathrm{L} \mathrm{CaCl}_{2}(\mathrm{pH} 9)$, and the mixture was added dropwise to $109 \mu \mathrm{L}$ of $11 \mathrm{mmol} / \mathrm{L} \mathrm{Na}_{2} \mathrm{HPO}_{4}(\mathrm{pH} 11)$ at $25^{\circ} \mathrm{C}$. 
After $1 \mathrm{~h}$, the complex resulting from the entrapment of ODN by $\mathrm{CaP}$ was collected by centrifugation. ODN concentration in the supernatant (ie, that was not entrapped by $\mathrm{CaP}$ ) was measured as described above. The precipitated complexes were washed twice with $\mathrm{H}_{2} \mathrm{O}$ and resuspended in $\mathrm{H}_{2} \mathrm{O}$ at a concentration of 50 and $500 \mu \mathrm{g} \mathrm{ODN} / \mathrm{mL}$ for in vitro and in vivo studies, respectively.

\section{Cell culture}

The mouse macrophage-like RAW264 cell line (RCB0535) and mouse fibrosarcoma L929 cell line (RCB1451) were purchased from RIKEN BioResource Center (Tsukuba, Japan). The human monocyte-like THP-1 cell line (ATCC ${ }^{\circledR}$ TIB$202^{\mathrm{TM}}$ ) was purchased from American Type Culture Collection (Manassas, VA, USA). Minimum Essential Medium supplemented with $10 \%$ fetal bovine serum (FBS) (SigmaAldrich, St Louis, MO, USA), 1\% penicillin/streptomycin (P/S; Thermo Fisher Scientific), and 1\% nonessential amino acid solution (Wako Pure Chemical Industries, Osaka, Japan) was used for RAW264 cell cultures. Dulbecco's Modified Eagle's Medium (Sigma-Aldrich) supplemented with 5\% FBS was used for L929 cell cultures. Roswell Park Memorial Institute 1640 medium (Thermo Fisher Scientific) supplemented with $10 \%$ FBS and $1 \%$ P/S was used for THP-1 cell cultures. Cells were seeded in a 96-well plate at a density of $1 \times 10^{5}$ cells/well $\left(5 \times 10^{5}\right.$ cells $\left./ \mathrm{mL}\right)$. After $18 \mathrm{~h}$, free ODN (final concentration: $50 \mu \mathrm{g} / \mathrm{mL}$ ) or ODN complex (final concentration: $5 \mu \mathrm{g} / \mathrm{mL}$ ) was added to the culture medium, and RAW264 and THP- 1 cells were cultured for another $6 \mathrm{~h}$ while L929 cells were cultured for another $24 \mathrm{~h}$ to evaluate the induction of IFN- $\beta$ and IL-12 transcripts. Cell viability was assayed with Cell Counting Kit-8 (Dojindo Laboratories, Kumamoto, Japan).

\section{Analyses of relative transcript levels and transcription product levels of cytokines}

For analysis of relative transcript levels, total RNA was extracted from cells and purified using Isogen (Nippon Gene, Tokyo, Japan). The mRNA was converted to cDNA with reverse transcriptase (Takara Bio, Kusatsu, Japan) after DNase I treatment. IFN- $\beta$ and IL-12p40 transcript levels were measured by quantitative real-time PCR (LightCycler 2.0; Roche Applied Science) with SYBR Green and the primers listed in Tables S1 and S2, and normalized to that of glyceraldehyde 3-phosphate dehydrogenase.

To analyze the transcription product levels, we collected the culture medium and diluted it with water. The transcription product level of IFN- $\beta$ in the diluted culture medium was assayed using a VerKine ${ }^{\mathrm{TM}}$ Mouse Interferon-beta ELISA Kit (PBL Assay Science, Piscataway, NJ, USA).

\section{Confocal fluorescence microscopy}

Cells stimulated for 1 or $4 \mathrm{~h}$ with either free or complexed FITC-labeled ODNs were fixed for 15 min with $4 \%$ (w/v) paraformaldehyde at $25^{\circ} \mathrm{C}$, washed twice with phosphatebuffered saline (PBS), and then permeabilized with $0.2 \%$ Tween- 20 for $5 \mathrm{~min}$ at $25^{\circ} \mathrm{C}$ before blocking with $3 \%$ bovine serum albumin for $1 \mathrm{~h}$ at $4^{\circ} \mathrm{C}$. The cells were then incubated overnight at $4^{\circ} \mathrm{C}$ with rabbit anti-lysosome associated membrane protein (LAMP)-1 antibody (Abcam, Cambridge, UK) followed by Alexa 555-labeled goat anti-rabbit IgG (Thermo Fisher Scientific) for $1 \mathrm{~h}$ at $25^{\circ} \mathrm{C}$. The cells were washed twice with PBS and then treated with an Antifade kit (Thermo Fisher Scientific). Fluorescence imaging was performed on a TCS SP5 confocal laser scanning microscope (Leica Microsystems, Wetzlar, Germany).

\section{Characterization of complexes}

Hydrodynamic size and zeta potential of complexes were measured using a laser diffraction particle size analyzer (SALD-2100; Shimadzu, Kyoto, Japan) and laser electrophoresis zeta-potential analyzer (ELSZ-1000; Otsuka, Tokyo, Japan), respectively.

For scanning electron microscopy (SEM), CaP and ds CpG-B-PD consisting of 72 base pairs (bp) entrapped by $\mathrm{CaP}$ (ds CpG-B72-PD/CaP) were resuspended in ethanol and sonicated for $2 \mathrm{~min}$. The suspension was added dropwise onto a silicon wafer that was desiccated at room temperature and then coated with platinum for SEM analysis (JSM-7000F; JEOL, Tokyo, Japan) at an accelerating voltage of $7 \mathrm{kV}$. Elemental analysis was carried out by energy-dispersive X-ray (EDX) spectroscopy (JED-2200; JEOL) combined with SEM.

The crystalline phase composition of $\mathrm{CaP}$ was examined by X-ray diffraction (XRD) (MiniFlex 300/600+; Rigaku, Tokyo, Japan) using an X-ray source with the potential set at $40 \mathrm{kV}$ and current set at $15 \mathrm{~mA}$. The specimens were scanned in a range from $5^{\circ}$ to $60^{\circ}$ at a speed of $0.02^{\circ} / \mathrm{s}$. Patterns were analyzed using a model auto-matched to the International Centre for Diffraction Data database. The structural characteristics and vibration bonds of $\mathrm{CaP}$ were analyzed by Fourier transform infrared (FTIR) spectroscopy (IRTracer-100; Shimadzu). For the analysis, $\mathrm{CaP}$ was prepared as a finely ground powder along with potassium bromide $(2 \%-10 \%$, $\mathrm{w} / \mathrm{w})$ and then formed into a transparent pellet using a crimping machine. Pellets were dried under vacuum for $30 \mathrm{~min}$ 
before FTIR detection. Spectra were recorded from 400 to $4,000 \mathrm{~cm}^{-1}$ in steps of $4 \mathrm{~cm}^{-1}$.

\section{Degradation of $\mathrm{CaP}$ at various $\mathrm{pH}$}

The $\mathrm{pH}$ of PBS (originally $\mathrm{pH}$ 7.4) was adjusted with $1 \mathrm{~mol} / \mathrm{L}$ $\mathrm{HCl}$. CaP collected by centrifugation was resuspended in solutions with different $\mathrm{pH}$ values. After $1 \mathrm{~h}$, the optical density (OD) at $320 \mathrm{~nm}$ was measured with a spectrophotometer (NanoDrop 2000; Thermo Fisher Scientific). The degradation of $\mathrm{CaP}$ was calculated with the formula $\left(\mathrm{OD}_{\text {various }} \mathrm{pH}^{\prime}\right.$ $\left.\mathrm{OD}_{\mathrm{pH} 7.3}\right) \times 100 \%$. For visualization, FITC-labeled ODNs entrapped by $\mathrm{CaP}$ were resuspended in $\mathrm{PBS}(\mathrm{pH} 7.4)$ and $10 \mathrm{mmol} / \mathrm{L}$ acetic acid ( $\mathrm{pH} \mathrm{5.0)}$. After $1 \mathrm{~h}$, the FITC signal was detected by confocal microscopy.

\section{Immunization}

Animal studies were conducted with approval from the Animal Care and Use Committee at the National Institute for Materials Science according to the Guidelines for Proper Conduct of Animal Experiments established by the Science Council of Japan. C57BL/6J mice (5 weeks old) were obtained from Charles River Laboratories Japan (Yokohama, Japan). A $200 \mu \mathrm{L}$ volume of vaccine solution containing $200 \mu \mathrm{g}$ ovalbumin (OVA) (Sigma-Aldrich) alone or mixed with $50 \mu \mathrm{g}$ CpG ODNs complexed with Lipo or $\mathrm{CaP}$ was subcutaneously injected into the back of 6-week-old mice twice at a 1-week interval. One week after the second injection, mice were euthanized with overdose of isoflurane (DS Pharma Animal Health, Osaka, Japan), and peripheral blood was collected from the caudal vena cava.

\section{Estimation of OVA-specific CD8 ${ }^{+} \mathrm{T}$ cell abundance and OVA-specific antibodies}

A portion of the collected peripheral blood was treated with EDTA/3K. A $10 \mu \mathrm{L}$ volume of T-Select H-2K ${ }^{\mathrm{b}}$ OVA Tetramer-SINFEKL-phycoerythrin (PE) (TS-5001-1C; Medical \& Biological Laboratories, Nagoya, Japan) was added to 50-100 $\mu \mathrm{L}$ EDTA-treated blood, and the mixture was allowed to stand at $25^{\circ} \mathrm{C}$ for $20 \mathrm{~min}$ before adding $1 \mu \mathrm{L}$ of mouse anti-CD3 PE-cyanine 5-conjugated antibody (Thermo Fisher Scientific) and $1 \mu \mathrm{L}$ of mouse anti-CD8 FITC-conjugated monoclonal antibody (KT15) (Medical \& Biological Laboratories). After $20 \mathrm{~min}, 500 \mu \mathrm{L}$ Optilyse C (Beckman Coulter, Brea, CA, USA) was added to the blood to induce hemolysis, and the mixture was allowed to stand for $10 \mathrm{~min}$ before adding $500 \mu \mathrm{L}$ PBS. The cell suspension was purified on a cell sorter (SH800; Sony, Tokyo, Japan).
To identify OVA-specific $\mathrm{CD}^{+} \mathrm{T}$ cells, lymphocytes were gated on the basis of a forward scatter (FSC)-vs-side scatter (SSC) density plot, and then developed to SSC-vs-CD3 density plot. The $\mathrm{CD}^{+}$population was further developed into an OVA tetramer-vs-CD8 density plot.

To obtain serum, peripheral blood was centrifuged at $1,800 \times g$ for $15 \mathrm{~min}$ at $4^{\circ} \mathrm{C}$. The levels of OVA-specific IgG1 and IgG2a were assayed using mouse anti-OVA IgG1 and IgG2a assay kits (both from Chondrex, Redmond, WA, USA).

\section{Statistics}

Statistical significance for in vitro data was evaluated with the two-tailed unpaired Student's $t$-test. For multiple comparisons, the $p$-value for significance was corrected with the Bonferroni method. For in vivo data, all groups were compared by analysis of variance followed by Tukey's honestly significant difference post hoc test and Ryan's method. A $p$-value $<0.05$ was considered statistically significant.

\section{Results}

\section{ds CpG-B-PD complex is a potent type-I IFN inducer}

ODN sequences used in this study are shown in Box 1. ss ODN2006 (hereafter referred to as ss CpG-B24-PT) is a conventional CpG-B ODN consisting of 24 PT nucleotides (nt) and three CpG motifs (GTCGTT). Although complexation of $\mathrm{CpG}-\mathrm{B}$ with cationic materials reportedly converts CpG-B from proinflammatory cytokine inducer to type-I IFN inducer, ${ }^{29-31}$ there was no induction of IFN- $\beta$ when mouse macrophage-like RAW264 cells expressing TLR9 were stimulated with ss CpG-B24-PT complexed with Lipo, a commercially available cationic liposome (Figure 1A). On the other hand, the complex of ss CpG-B24-PD - which has a PD backbone - with Lipo showed a high capacity for inducing IFN- $\beta$ as compared to the ss CpG-B24-PT complex (Figure 1A), while the complex of ds CpG-B24-PD and Lipo had a greater capacity to induce IFN- $\beta$ than the ss CpG-B24-PD complex (Figure 1B).

ds CpG-B24-PD consists of 24 bp with three CpG motifs. We prepared ds CpG-B48-PD and ds CpG-B72-PD, which have two and three linked ds CpG-B24-PD sequences, respectively (ie, six and nine $\mathrm{CpG}$ motifs, respectively) (Box 1). IFN- $\beta$ induction in the ds CpG-B-PD-Lipo complexes increased with the number of $\mathrm{CpG}$ motifs (Figure 1C). We observed IFN- $\beta$ induction by ds CpG-free24-PD, ds CpG-free48-PD, and ds CpG-free72-PD complexes that 
Box I Sequences of $C_{p G}$ and $C_{p G}$-free ODNs used in this study

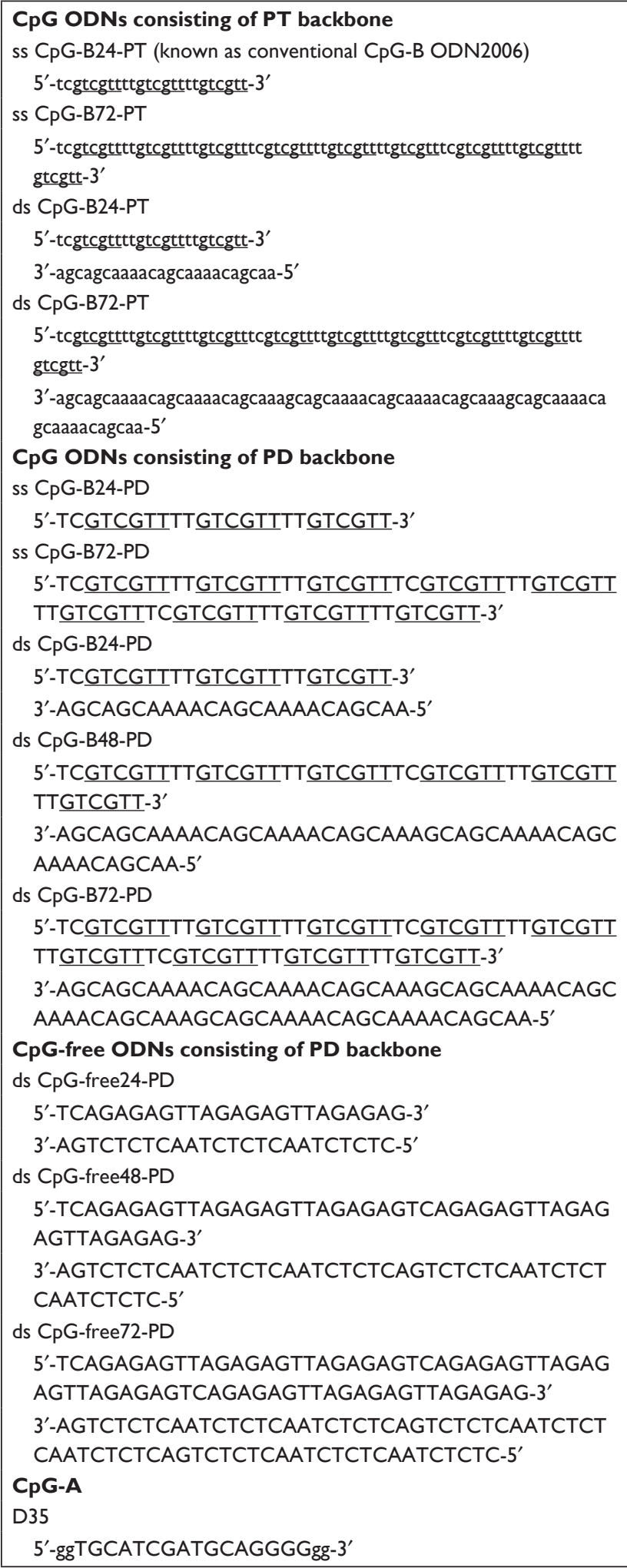

Notes: Small letter, PT-modified nucleotide; capital letter, native PD nucleotide; underline, $C_{P G}$ motif. ds ODN was prepared by the hybridization of two ss ODNs.

Abbreviations: $C_{P} G$, cytosine-guanine; ODNs, oligodeoxynucleotides; PT, phosphorothioate; ss, single stranded; CpG-B, class B CpG; ds, double stranded; PD, phosphodiester; CPG-A, class A CPG. were 24, 48, and 72 bp ODNs, respectively, without $\mathrm{CpG}$ motifs, although the induction level was lower than that by the complex of B-DNA, which is a ligand of cytosolic DNA receptors (Figure 1C). ${ }^{41}$ In this experiment, we also analyzed the level of IFN- $\beta$ secreted into the culture medium and confirmed the correlation between the transcript level and secretion level in RAW264 cells (Figure S2). IFN- $\beta$ induction by CpG-free ODN complexes may be mediated by cytosolic DNA receptors that recognize ds PD DNA in a CpG-independent manner. IFN- $\beta$ levels induced by the ds CpG-B24-PD, ds CpG-B48-PD, and ds CpG-B72-PD complexes were higher than those induced by ds CpG-free ODN complexes, suggesting that IFN- $\beta$ induction by the former is highly dependent on the presence of $\mathrm{CpG}$ motifs. We evaluated IFN- $\beta$ induction potential of ds CpG-B-PT (ds CpGB24-PT and ds CpG-B72-PT) complexed with Lipo but did not observe any significant induction (Figure 1D).

We previously reported that free ss CpG-B72-PD is a proinflammatory cytokine inducer. ${ }^{42}$ Free ds CpG-B72-PD induced IL-12 in RAW264 cells, although the level was markedly lower than that induced by free ss CpG-B72-PD (Figure S3). On the other hand, free ds CpG-B72-PD showed no capacity to induce IL-12. These results imply that free ds CpG-B72-PD is also a proinflammatory cytokine inducer, and that this activity depends on the $\mathrm{CpG}$ motif.

\section{$\mathrm{CaP}$ is an effective material for ds CpG- B-PD complexation}

We tested another commercially available cationic liposome, DOTAP, for complexation with ds CpG-B72-PD. The level of IFN- $\beta$ induced by ds CpG-B72-PD complexed with DOTAP was significantly lower than that induced by ds CpG-B72-PD complexed with Lipo (ds CpG-B72-PDLipo) (Figure 2A). This suggests that the material used for ds CpG-B-PD ODN complexation influences the degree of IFN- $\beta$ induction. Although effective, Lipo is expensive and can only be used in laboratory settings. Important considerations for adjuvants - especially those for high-coverage vaccines - are manufacturing cost as well as adjuvant effect. We therefore examined whether $\mathrm{CaP}$ can be used for complexation of ds CpG-B-PD, since the ingredients required for $\mathrm{CaP}$ preparation are inexpensive and production is simple and readily scalable. We complexed ds CpG-B72-PD with $\mathrm{CaP}$ by entrapment of ds $\mathrm{CpG}-\mathrm{B} 72-\mathrm{PD}$ by $\mathrm{CaP}$ (ds CpG-B72-PD/CaP) and by adsorption of ds CpG-B72-PD onto the $\mathrm{CaP}$ surface (ds $\mathrm{CpG}-\mathrm{B} 72-\mathrm{PD}-\mathrm{CaP}$ ) (Figure S4A and $\mathrm{B}$ ). The complexation efficiency of ds CpG-B72-PD was 
A

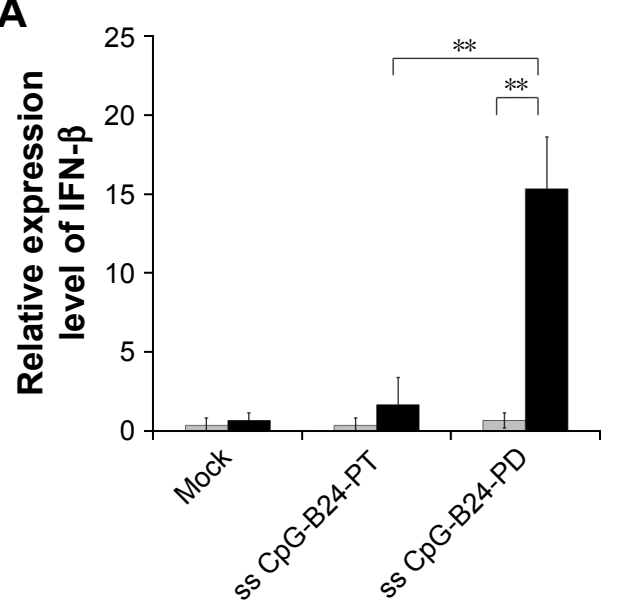

B

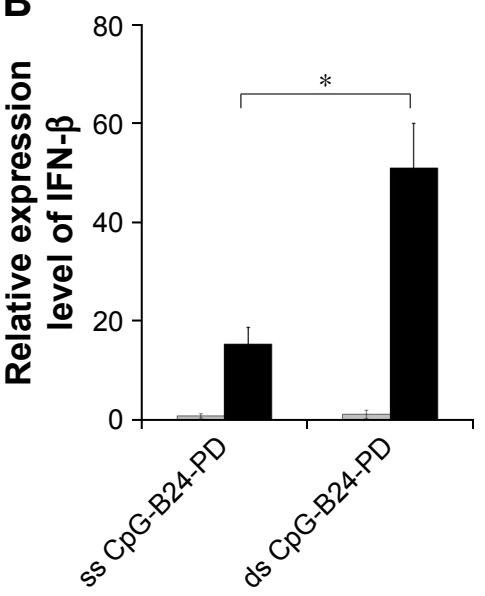

W/o lipofectamine $\mathbf{W i t h}$ lipofectamine

C

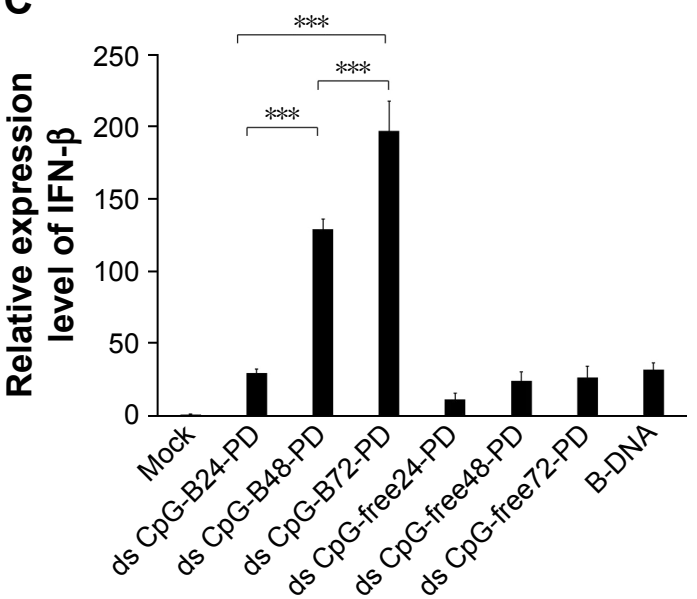

D

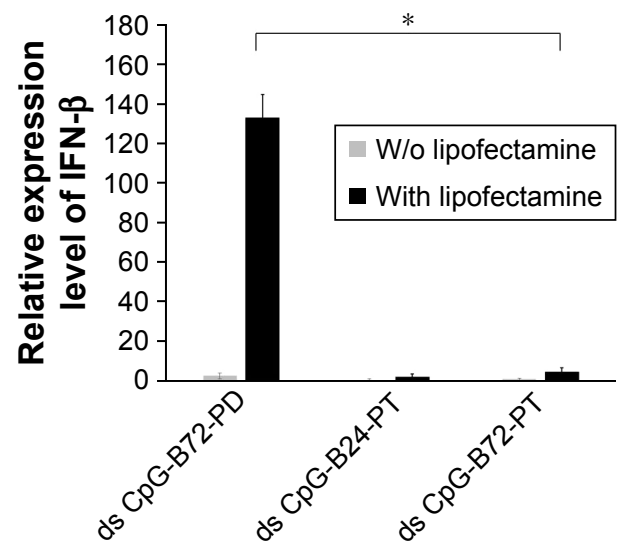

Figure I Induction of IFN- $\beta$ transcript in mouse macrophage-like RAW264 cells stimulated with CpG ODN.

Notes: (A) IFN- $\beta$ is induced to a greater degree by a PD as compared to a PT backbone in ss 24 nt CpG-B (CpG-B24) when complexed with Lipo. Mock, Opti-MEM. (B) IFN- $\beta$ is induced to a greater degree by ds as compared to ss CPG-B24-PD when complexed with Lipo. (C) Effect of the number of CpG motifs in ds CpG-B-PD complexed with Lipo on IFN- $\beta$ induction. ds CpG-B24-PD, ds CpG-B48-PD, and ds CpG-B72-PD contain three, six, and nine CpG motifs, respectively. Mock, Opti-MEM alone. (D) IFN- $\beta$ was not induced by ds CpG-B24-PT and ds CpG-B72-PT complexed with Lipo. Data represent mean \pm SD $(n=3)$. ${ }^{*} p<0.05$, ** $p<0.025$, and $* * * p<0.0125$ (two-tailed unpaired Student's $t$-test).

Abbreviations: IFN, interferon; CpG, cytosine-guanine; ODN, oligodeoxynucleotide; PD, phosphodiester; PT, phosphorothioate; ss, single stranded; nt, nucleotide; CpG-B, class B CpG; Lipo, Lipofectamine 2000; ds, double stranded; w/o, without.

approximately $100 \%$ in both the entrapment and adsorption methods. Assuming that all $\mathrm{Ca}^{2+}$ was used for $\mathrm{CaP}$ formation, the amount of ds CpG-B72-PD loaded was estimated to be around 68 and $65 \mu \mathrm{g} / \mathrm{mg} \mathrm{CaP}$, respectively. The mean hydrodynamic size of naked CaP was $1,115 \pm 332 \mathrm{~nm}$, whereas the mean sizes of ds CpG-B72-PD/CaP and ds CpG-B72-PD-CaP were $437 \pm 135$ and $717 \pm 183 \mathrm{~nm}$, respectively (Figure S5). The zeta potential was $-5.46 \mathrm{mV}$ for naked CaP, $-16.1 \mathrm{mV}$ for ds CpG-B72-PD/CaP, and -28.1 mV for ds CpG-B72PD-CaP. When RAW264 cells were stimulated with these complexes, a higher level of IFN- $\beta$ was observed in the presence of ds CpG-B72-PD/CaP (Figure 2B). IFN- $\beta$ level was about 1.4 times higher when induced by ds CpG-B72-PD/ $\mathrm{CaP}$ as compared to ds CpG-B72-PD-Lipo. On the other hand, the level of IFN- $\beta$ induction by ds CpG-B72-PD-CaP was about 30\% that by ds CpG-B72-PD-Lipo (Figure 2B). This indicates that the loading method affects the adjuvant effect of ds CpG-B72-PD, and that ds CpG-B72-PD entrapment by $\mathrm{CaP}$ is superior to ds $\mathrm{CpG}-\mathrm{B} 72-\mathrm{PD}$ adsorption onto the CaP surface for complexation. We also observed higher IFN- $\beta$ induction with ds CpG-B72-PD/CaP than with ss $\mathrm{CpG}$ B72-PD/CaP or ds CpG-free72-PD/CaP; the level of IFN- $\beta$ induced by ds $\mathrm{CpG}-\mathrm{B} 48-\mathrm{PD} / \mathrm{CaP}$ was approximately half of that induced by ds CpG-B72-PD/CaP (Figure 2C). However, ds CpG-B48-PD/CaP showed a higher capacity for induction than D35/CaP (CpG-A entrapped by CaP) (Figure 2D).

We also examined the capacity of ds CpG-B72-PD/CaP to induce IFN- $\beta$ via cytosolic DNA receptors using murine 

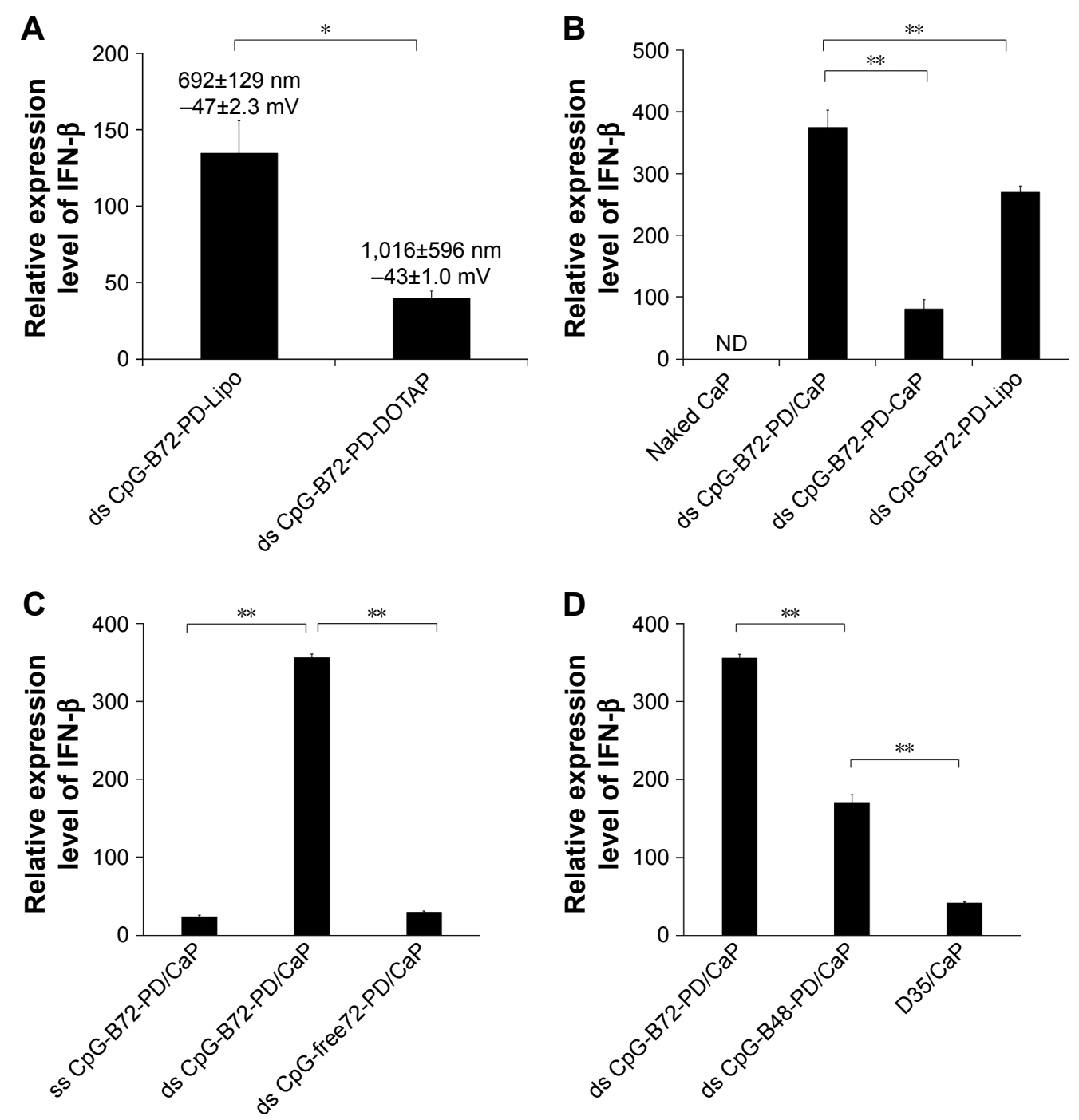

Figure 2 Carrier material determines the induction of IFN- $\beta$ by ds CpG-B-PD in RAW264 cells.

Notes: (A) Lipo is a superior carrier to DOTAP. Data labels show hydrodynamic size and zeta potential. (B) ds CpG-B72-PD entrapped by CaP (ds CpG-B72-PD/CaP) had the highest capacity for inducing IFN- $\beta$. ds CpG-B72-PD-CaP, ds CpG-B72-PD adsorbed onto the surface of CaP. (C) CpG-dependent IFN- $\beta$ induction was higher for ds CpG-B72-PD/CaP than for ss CpG-B72-PD/CaP. (D) Degree of IFN- $\beta$ induction by ds $C_{P}$ G-B-PD entrapped by CaP depends on the number of CpG motifs. ds CpG-B72-PD and ds CpG-B48-PD contain nine and six CpG motifs, respectively. D35/CaP, D35 entrapped by CaP; D35, conventional CpG-A. Data represent mean \pm SD ( $n=3$ ). * $p<0.05$ and $*^{*} p<0.025$ (two-tailed unpaired Student's $t$-test).

Abbreviations: IFN, interferon; ds, double stranded; PD, phosphodiester; CpG-B, class B CpG; Lipo, Lipofectamine 2000; DOTAP, N-[I-(2,3-dioleoyloxy)propyl]-N,N,Ntrimethylammonium methyl-sulfate; CaP, calcium phosphate; $C_{p} G$, cytosine-guanine; ss, single stranded; CpG-A, class A CpG; ND, not detected.

fibrosarcoma L929 cells and human monocyte-like THP-1 cells. Neither of these cell lines express TLR9 but have cytosolic DNA receptors. ${ }^{41}$ In L929 cells, IFN- $\beta$ induction was higher by B-DNA complexed with Lipo (B-DNALipo) than by ds CpG-B72-PD-Lipo (Figure S6A). In addition, the potential to induce IFN- $\beta$ was lower for B-DNA complexed with $\mathrm{CaP}$ (B-DNA/CaP) and ds CpG-B72-PD/ $\mathrm{CaP}$ as compared to B-DNA-Lipo and ds CpG-B72-PD-Lipo (Figure S6A). L929 and RAW264 cells are adherent, while THP-1 cells grow in suspension. Similar to L929 cells, in THP-1 cells IFN- $\beta$ induction was higher in the presence of B-DNA-Lipo as compared to ds CpG-B72-PD-Lipo (Figure S6B). On the other hand, IFN- $\beta$ was not induced by
B-DNA/CaP or ds CpG-B72-PD/CaP (Figure S6B), although $\mathrm{CaP}$ was internalized by suspended THP-1 cells and ODN molecules were localized in the cytosol (Figure S6C). These results suggest that ds $\mathrm{CpG}$-B72-PD has a lower capacity to induce IFN- $\beta$ via cytosolic DNA receptors than B-DNA and that ds CpG-B72-PD delivered by $\mathrm{CaP}$ does not significantly activate this pathway via cytosolic DNA receptors.

\section{Characterization of $\mathrm{CaP}$}

Naked $\mathrm{CaP}$ is an agglomerate consisting of elongated flakes with a long side $\leq 200 \mathrm{~nm}$ (Figure $3 \mathrm{~A}$ ). On the other hand, ds CpG-B72-PD/CaP is an agglomerate of petal-like flakes with a long side $<150 \mathrm{~nm}$ (Figure 3B). The EDX spectroscopy 
A
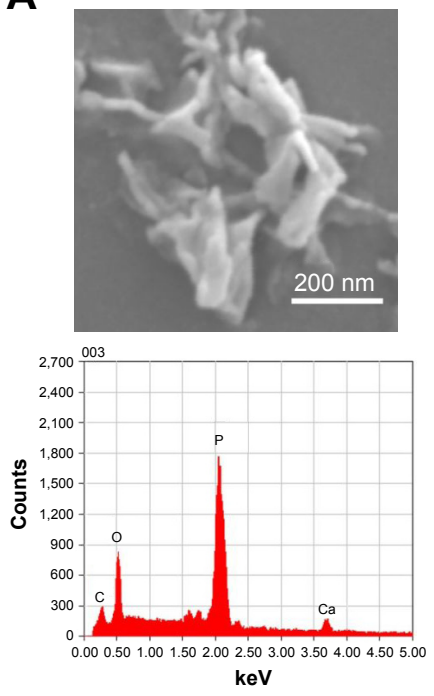

B
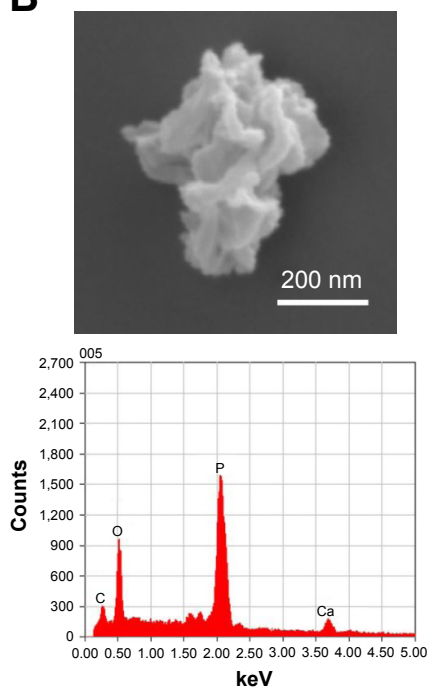

C

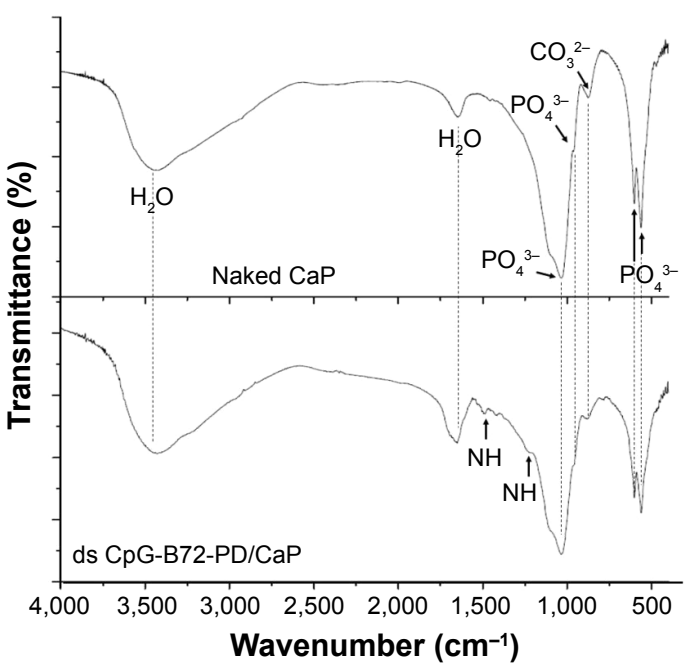

D

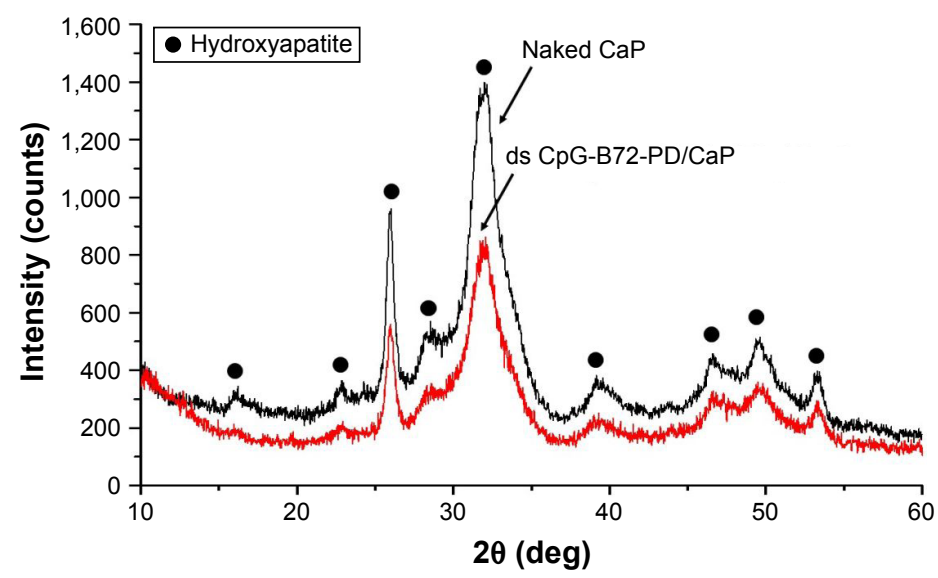

Figure 3 Characterization of naked $\mathrm{CaP}$ and ds CpG-B72-PD/CaP.

Notes: (A) Morphology and elemental composition of naked CaP. Upper panel, SEM image; lower panel, EDX spectrum. (B) Morphology and elemental composition of ds CPG-B72-PD/CaP. Upper panel, SEM image; lower panel, EDX spectrum. (C) FTIR spectra of naked CaP (top) and ds CpG-B72-PD/CaP (bottom). (D) XRD spectra of naked $\mathrm{CaP}$ (top) and ds CpG-B72-PD/CaP (bottom).

Abbreviations: CaP, calcium phosphate; ds, double stranded; CPG-B, class B cytosine-guanine; PD, phosphodiester; SEM, scanning electron microscopy; EDX, energydispersive X-ray; FTIR, Fourier transform infrared; XRD, X-ray diffraction.

analysis detected $\mathrm{C}, \mathrm{O}, \mathrm{P}$, and $\mathrm{Ca}$ in both naked $\mathrm{CaP}$ and $\mathrm{ds}$ CpG-B72-PD/CaP (Figure 3A and B). In the FTIR spectrum of naked $\mathrm{CaP}$ (Figure $3 \mathrm{C}$ ), bands for the $\mathrm{P}-\mathrm{O}$ vibration of the orthophosphate group were observed at 560, 570, 958, and $1,034 \mathrm{~cm}^{-1}$. A band attributed to the $\mathrm{CO}_{3}{ }^{2-}$ stretching mode was observed at $862 \mathrm{~cm}^{-1}$. The bands for water vibration at 3,422 and 1,629 $\mathrm{cm}^{-1}$ provided evidence for the hydration of naked $\mathrm{CaP}$. In addition to these peaks, bands attributed to $\mathrm{NH}^{43}$ were detected at $1,210,1,400$, and $1,470 \mathrm{~cm}^{-1}$ in ds CpG-B72-PD/CaP (Figure 3C), suggesting the presence of ds CpG-B72-PD. The XRD analysis revealed that the crystal structure of both naked $\mathrm{CaP}$ and ds $\mathrm{CpG}-\mathrm{B} 72-\mathrm{PD} / \mathrm{CaP}$ was identical to a low-crystalline hydroxyapatite (product number 677418; Sigma-Aldrich) (Figure 3D).

We also examined the $\mathrm{pH}$-dependent degradation of $\mathrm{CaP}$ particles. Approximately $95 \%$ of $\mathrm{CaP}$ was degraded in a $\mathrm{pH} 5$ solution within $1 \mathrm{~h}$ (Figure $4 \mathrm{~A}$ and $\mathrm{B}$ ), implying that $\mathrm{CaP}$ can be easily degraded in the acidic environment of endosomes and lysosomes. RAW264 cells were incubated with FITC-labeled ODNs entrapped by $\mathrm{CaP}$ and examined by confocal fluorescence microscopy. A fluorescence signal corresponding to FITC was observed near the inner cell membrane and in late-endosomes/lysosomes-expressing LAMP-1 after $1 \mathrm{~h}$ (Figure 4C). FITC near the inner cell membrane was 
A

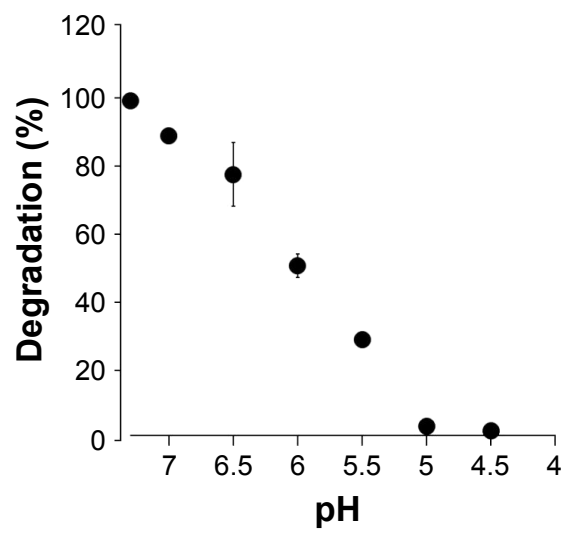

C

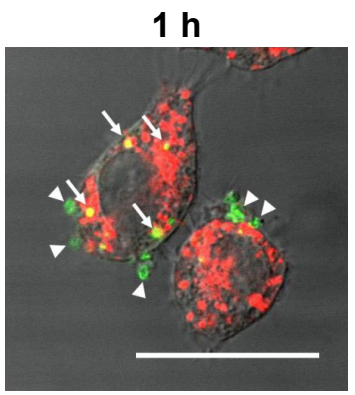

B
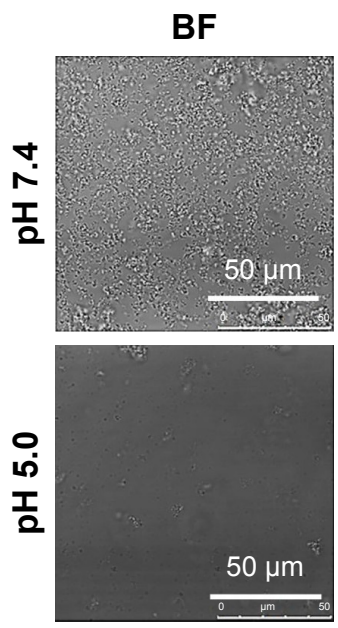

D 1.2

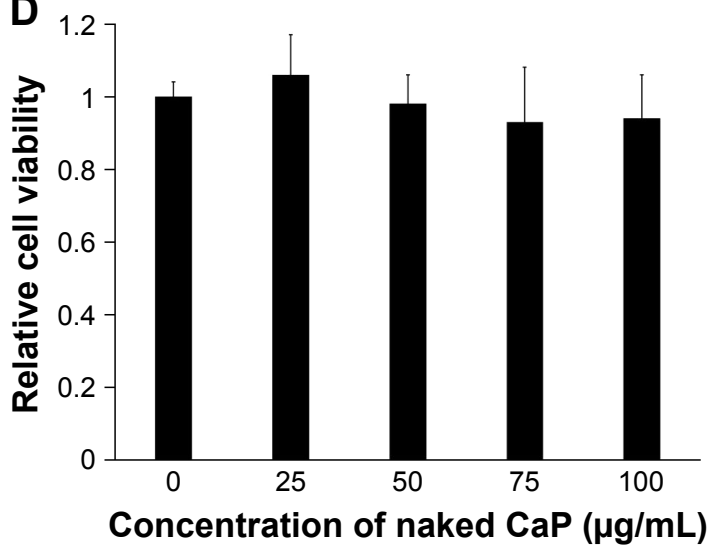

Figure 4 Degradation of $\mathrm{CaP}$ in an acidic environment and subcellular localization and cytotoxicity of CaP.

Notes: $(\mathbf{A}) \mathrm{pH}$-dependent degradation of $\mathrm{CaP}$. CaP was resuspended in solutions with various $\mathrm{pH}$; optical density at $320 \mathrm{~nm}$ was measured I h later. (B) FITC-labeled ODNs

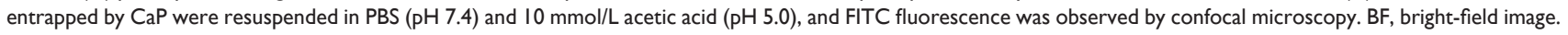
(C) Subcellular localization of ODN entrapped by CaP. FITC-labeled ODNs entrapped by CaP were applied to RAW264 cells. Green, FITC; red, LAMP-I; arrowhead, FITC near inner cell membrane; arrow, FITC in the late endosome or lysosome. (D) Cytotoxicity of CaP. RAW264 cells were treated with various concentrations of CaP, and cell viability was evaluated $24 \mathrm{~h}$ later.

Abbreviations: BF, bright-field; CaP, calcium phosphate; FITC, fluorescein isothiocyanate; ODNs, oligodeoxynucleotides; PBS, phosphate-buffered saline.

presumed to be associated with early endosomes, given that the signal was also detected in late endosomes/lysosomes, which are part of the same endocytic transport route. On the other hand, FITC was observed throughout the cell after $4 \mathrm{~h}$ (Figure 4C), suggesting that ds CpG-B72-PD had escaped from endosomes and/or lysosomes into the cytosol due to degradation of $\mathrm{CaP}$ in the acidic environment in these organelles. Although CaP degradation increases intracellular $\mathrm{Ca}^{2+}$ concentration, no cytotoxicity was observed (Figure 4D).

\section{Adjuvant effect of ds CpG-B72-PD/CaP}

We next examined whether ds $\mathrm{CpG}-\mathrm{B} 72-\mathrm{PD} / \mathrm{CaP}$ induces antigen-specific $\mathrm{CD} 8^{+} \mathrm{T}$ cells by subcutaneously injecting ds CpG-B72-PD/CaP or ds CpG-B72-PD-Lipo in conjunction with OVA (ds CpG-B72-PD/CaP + OVA or ds CpGB72-PD-Lipo + OVA, respectively) into mice twice at a 1 -week interval. One week after the last injection, the ratio of
OVA-specific $\mathrm{CD}^{+} \mathrm{T}$ cells to total $\mathrm{CD}^{+} \mathrm{T}$ cells was 10 -fold higher in the group vaccinated with ds $\mathrm{CpG}-\mathrm{B} 72-\mathrm{PD} / \mathrm{CaP}+$ OVA than in mice vaccinated with OVA alone (Figures $5 \mathrm{~A}$ and $\mathrm{S} 7 \mathrm{~A}$ and $\mathrm{B})$. OVA alone did not increase the ratio of OVA-specific $\mathrm{CD}^{+} \mathrm{T}$ cells (Figure S8A). Although we observed a higher level of IFN- $\beta$ induction in RAW264 cells stimulated with ds $\mathrm{CpG}-\mathrm{B} 72-\mathrm{PD} / \mathrm{CaP}$ than with ds $\mathrm{CpG}-$ B72-PD-Lipo (Figure 2B), no significant difference was observed in the ratio of OVA-specific $\mathrm{CD}^{+} \mathrm{T}$ cells between mice vaccinated with ds $\mathrm{CpG}-\mathrm{B} 72-\mathrm{PD} / \mathrm{CaP}+\mathrm{OVA}$ and $\mathrm{ds}$ CpG-B72-PD-Lipo + OVA (Figures 5A and S7C).

We also analyzed serum IgG1 and IgG2a antibody levels 1 week after the last injection. Administration of OVA alone significantly increased the level of OVA-specific IgG1 antibody (Figure S8B). The average level of OVA-specific IgG1 antibody in mice vaccinated with ds CpG-B72-PD/ $\mathrm{CaP}+\mathrm{OVA}$ and ds CpG-B72-PD-Lipo + OVA was 3- and 

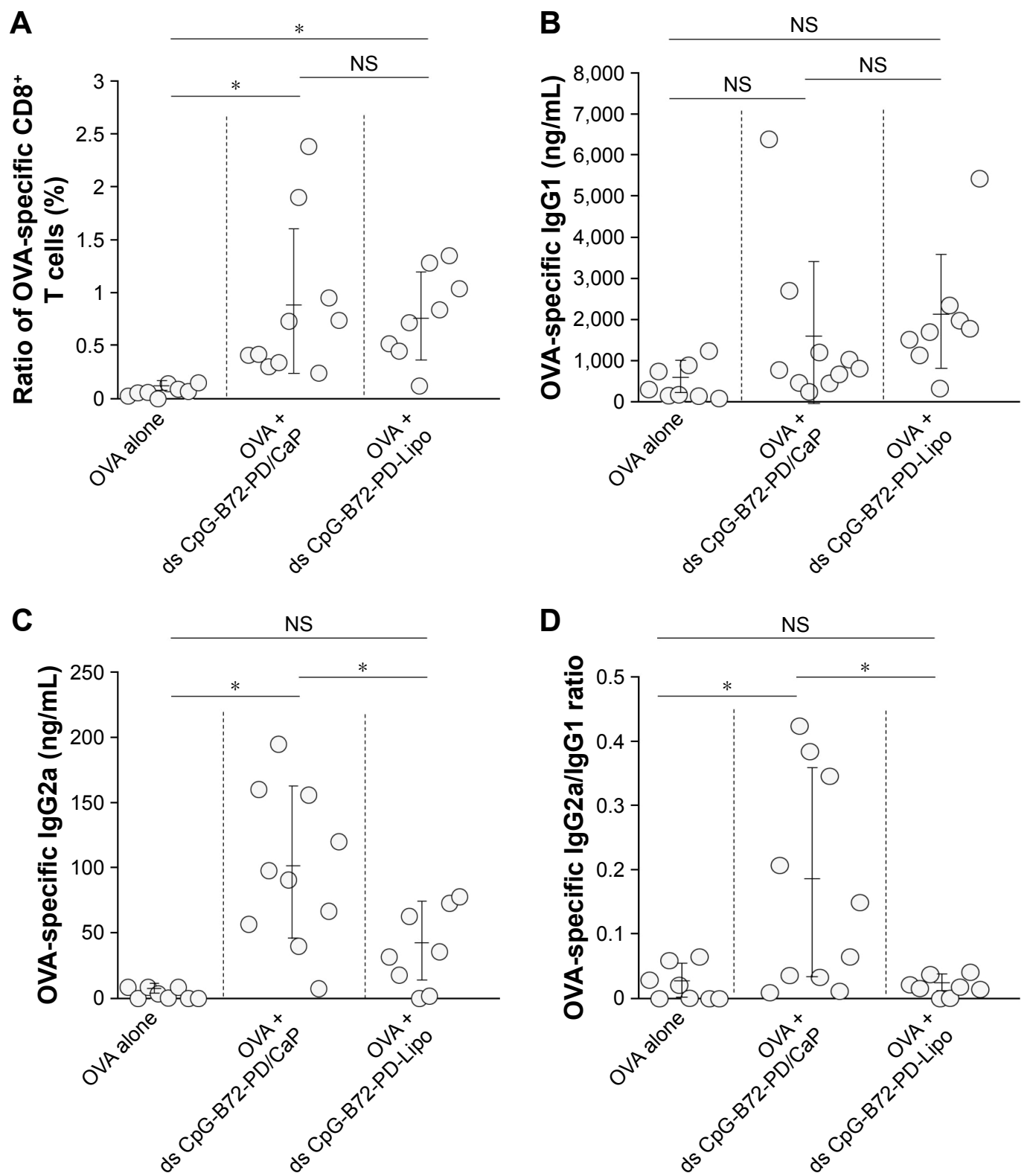

Figure 5 OVA-specific immune responses in mice.

Notes: (A) Ratio of OVA-specific CD8 ${ }^{+} \mathrm{T}$ cells to total $\mathrm{CD}^{+} \mathrm{T}$ cells in peripheral blood. Each circle corresponds to the ratio of OVA-specific CD8 ${ }^{+} \mathrm{T}$ cells in an individual mouse, and horizontal lines show mean \pm SD. (B) OVA-specific lgGI antibody level in serum. Each circle corresponds to the OVA-specific lgGI antibody level in an individual mouse. (C) OVA-specific lgG2a antibody level in serum. Each circle corresponds to the OVA-specific lgG2a antibody level in an individual mouse. (D) Ratios of OVA-specific IgG2a to OVA-specific lgGI in individual mouse (circles) and group average \pm SD (horizontal lines). * $<<0.05$ (analysis of variance followed by Tukey's honestly significant difference post hoc test and Ryan's method).

Abbreviations: OVA, ovalbumin; ds, double stranded; CpG-B, class B cytosine-guanine; PD, phosphodiester; CaP, calcium phosphate; Lipo, Lipofectamine 2000; NS, not significant.

4-fold higher than those in mice vaccinated with OVA alone, respectively, although these were not statistically significant differences (Figure 5B). On the other hand, ds CpG-B72-PD/CaP + OVA elicited 23- and 2-fold higher induction of OVA-specific IgG2a as compared to OVA alone and ds CpG-B72-PD-Lipo + OVA, respectively (Figure 5C). The average induction level of OVA-specific IgG2a in the ds CpG-B72-PD-Lipo + OVA group was 11-fold higher than that in mice injected with OVA alone, but the difference was not statistically significant. OVA alone did not trigger any detectable OVA-specific IgG2a antibody response (Figure S8C). Although no increase in anti-OVA IgG2a/IgG1 ratio was observed in the ds CpGB72-PD-Lipo + OVA as compared to the OVA-only group, mice vaccinated with ds $\mathrm{CpG}-\mathrm{B} 72-\mathrm{PD} / \mathrm{CaP}+\mathrm{OVA}$ showed a significantly increased ratio (Figure 5D), suggesting a shift toward a Th1-dominated response. One of the triggers for Th1-biased pathway activation is the differentiation of naïve 

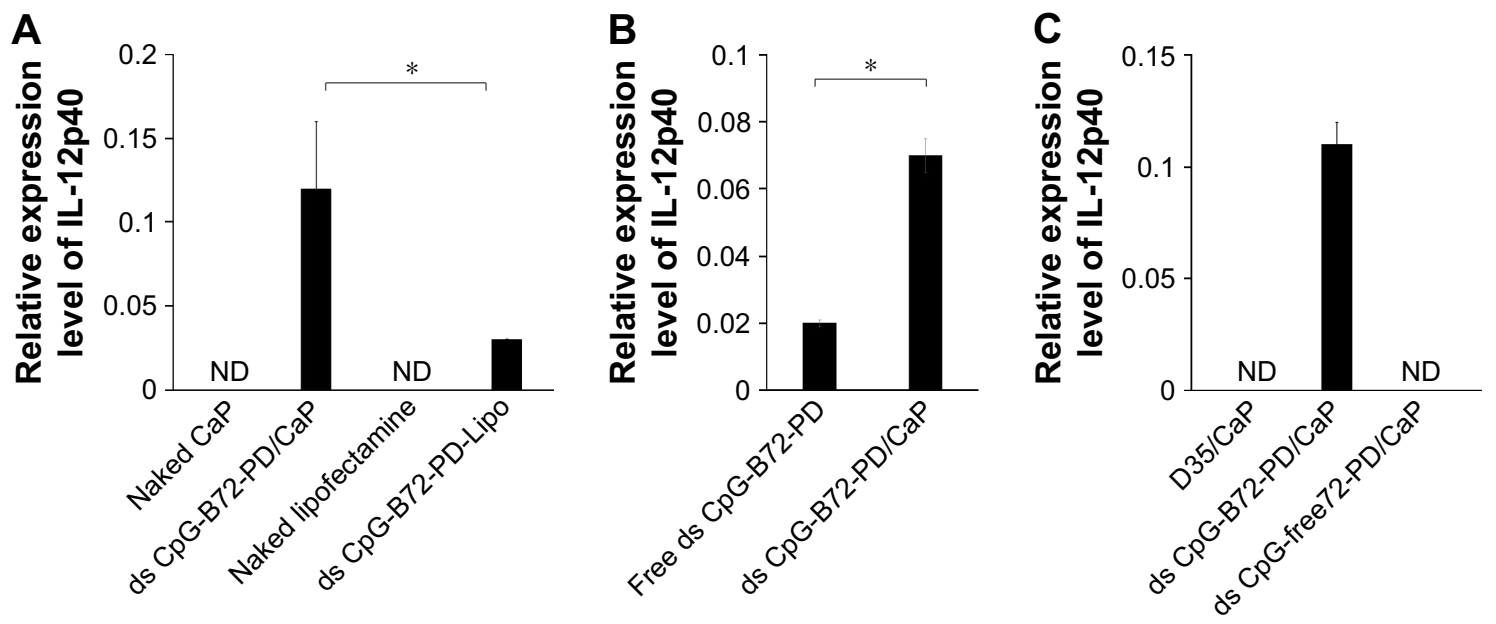

Figure 6 Induction of IL-12 transcript in RAW264 cells.

Notes: (A) CaP was a superior carrier to Lipo for IL-12 induction by ds CpG-B72-PD. (B) Entrapment of ds CPG-B72-PD enhanced IL-I2 induction. (C) IL-I2 was induced to a greater degree by ds CpG-B72-PD/CaP than by D35/CaP or ds CpG-free72-PD/CaP. D35/CaP, D35 entrapped by CaP; D35, conventional CpG-A. Data represent mean \pm SD ( $n=3)$. * $p<0.05$ (two-tailed unpaired Student's $t$-test).

Abbreviations: IL, interleukin; CaP, calcium phosphate; Lipo, Lipofectamine 2000; ds, double stranded; CpG-B, class B CpG; PD, phosphodiester; CpG, cytosine-guanine; CpG-A, class A CpG; ND, not detected.

T cells to Th1 cells induced by IL-12 secreted by antigenpresenting cells. ${ }^{44-46}$ We therefore examined IL-12 induction in RAW264 cells stimulated with ds CpG-B72-PD/CaP and found that IL-12 was induced to a greater degree in the ds CpG-B72-PD/CaP than in the ds CpG-B72-PD-Lipo group (Figure 6A). In addition, ds $\mathrm{CpG}-\mathrm{B} 72-\mathrm{PD} / \mathrm{CaP}$ showed a higher capacity for IL-12 induction than free ds CpG-B72-PD (Figure 6B), whereas D35/CaP and ds CpG-free72-PD/CaP did not induce IL-12 (Figure 6C).

\section{Discussion}

Alum is widely used as a vaccine adjuvant; although it activates humoral immunity, it has poor capacity for inducing cellular immunity. Type-I IFN induced by antigen-presenting cells such as pDCs is involved in the activation of cellular immunity. ${ }^{22-24}$ It has been reported that complexation of conventional CpG-B (ss CpG-B-PT) with materials such as cationic peptides, polycations, and polysaccharides confers conventional $\mathrm{CpG}-\mathrm{B}$ with the capacity to induce type-I IFN. ${ }^{28-32}$ In this study, we demonstrate that in a complex with Lipo, ds CpG-B72-PD designed based on the ss CpG-B24-PT sequence (known as the conventional CpG-B ODN2006) is a potent inducer of IFN- $\beta$ as compared to ss CpG-B24-PT. ds CpG-B72-PD is a proinflammatory inducer that is similar to conventional $\mathrm{CpG}-\mathrm{B}$ but has a ds native PD backbone instead of an ss artificial PT backbone.

DNA consisting of a PT backbone is more resistant to nuclease digestion than natural PD DNA, but has been reported to cause thrombocytopenia, anemia, and neutropenia in rats and arthritis in mice. ${ }^{33,34}$ Furthermore, a higher risk of adverse events was demonstrated in clinical trials using conventional CpG-B-PT. ${ }^{47,48}$ To avoid this toxicity, CpG ODNs with a native PD backbone were developed. MGN1703 consisting entirely of PD backbone, which has two 30 nt loops containing three CpG motifs and a 28 bp stem linking these loops stimulates the release of IFN- $\alpha$ and proinflammatory cytokines such as IFN- $\gamma$, IL-6, IL-12, and TNF- $\alpha$ by human peripheral blood mononuclear cells, resulting in activation of both cellular and humoral immunity. ${ }^{49,50}$ In MGN1703, CpG motifs are present in ss loops, implying that a ds CpG motif is not essential for type-I IFN induction. Additionally, MGN1703 is not required for complexation and type-I IFN induction, and its safety in humans was verified in a Phase I clinical trial. ${ }^{51}$ An X-shaped ds PD CpG ODN can be formed by self-assembly of four complementary ss PD CpG ODNs, ${ }^{52}$ while one composed of four ss PD CpG ODN molecules forms a self-ligated complex through complementarity with the sticky ACGT sequence at the $5^{\prime}$ end. ${ }^{53}$ These non-self- and self-ligated X-shaped ds PD CPG ODN induced IFN- $\beta$ in addition to IL-12 and TNF- $\alpha$ in mouse bone marrow-derived primary DCs; ${ }^{53}$ the degree of IFN- $\beta$ induction was higher for the self-ligated as compared to the non-self-ligated molecule. Our uncomplexed ds CpG-B72-PD - which was incapable of inducing IFN- $\beta$ has a linear structure without branching, in contrast to the self-ligated X-shaped ds PD CpG ODN which had more branches than the non-self-ligated form. This suggests that free ds PD CpG ODN without complexation can potentially be endowed with type-I IFN induction capacity via branching. In a previous study, ds PD CpG ODN molecules with 
polypod structures (tri-, tetra-, penta-, hexa-, and octapod) were synthesized via self-assembly of three to eight ss PD CpG ODNs. ${ }^{54}$ In RAW264 cells, the levels of proinflammatory cytokines including IL- 6 and TNF- $\alpha$ were higher in cells stimulated with a higher branch (polypod) number. Although these authors did not demonstrate IFN- $\beta$ induction in cells stimulated with polypod-like ds PD CpG ODN, CD8 ${ }^{+}$T cell activation in mice subcutaneously injected with hexapod ds PD CpG ODN has been reported. ${ }^{55}$

For the crystal structure of $\mathrm{CaP}$ prepared for ds $\mathrm{CpG}-$ B72-PD complexation, we detected a band attributed to the $\mathrm{CO}_{3}{ }^{2-}$ group at $862 \mathrm{~cm}^{-1}$ in the FTIR spectrum. The band for the $\mathrm{CO}_{3}{ }^{2-}$ group of hydroxyapatite generally appears around 1,400-1,600 $\mathrm{cm}^{-1}$ (Figure S9), but we did not observe this band in our $\mathrm{CaP}$. Therefore, the crystal structure of our $\mathrm{CaP}$ was deduced to be identical to that of low-crystalline hydroxyapatite, but its chemical composition is different from that of hydroxyapatite, where the molar ratio of $\mathrm{Ca}$ to $\mathrm{P}$ is 1.67 . We loaded ds CpG-B72-PD by using adsorption and entrapment methods. Although the detailed mechanism by which ds CpG-B72-PD binds to the CaP surface in the adsorption method remains unclear, it has been reported that both $\mathrm{C}$ and $\mathrm{P}$ sites are involved in the electrostatic interaction, and play a critical role in the binding of DNA to the hydroxyapatite surface. ${ }^{56}$ In the complexation of ds CpGB72-PD with $\mathrm{CaP}$, the loading method influenced IFN- $\beta$ induction. In ds CpG-B72-PD-Lipo, ds CpG-B72-PD binds to the Lipo surface via electrostatic interactions (Figure S4C). Although ds CpG-B72-PD was also located on the surface of $\mathrm{CaP}$ in ds CpG-B72-PD-CaP (Figure S4B), it showed a lower capacity for inducing IFN- $\beta$ than ds CpG-B72-PDLipo. ds CpG-B72-PD bound to the Lipo surface is thought to interact with endosomal TLR9. In contrast, in ds CpGB72-PD-CaP, most of the ds CpG-B72-PD molecules may be immediately released upon dissolution of $\mathrm{CaP}$ in the acidic environment of endosomes/lysosomes (Figure 7A) and thus lack the capacity to induce IFN- $\beta$. In ds CpG-B72-PD/ $\mathrm{CaP}$, which induced IFN- $\beta$ to a greater extent than ds $\mathrm{CpG}$ B72-PD-CaP, the CaP surface had randomly multimerized ds CpG-B72-PD exposed by the dissolution of the original surface (Figure 7B), which were presumed to interact with TLR9 to induce IFN- $\beta$ and IL- 12 .

\section{A}
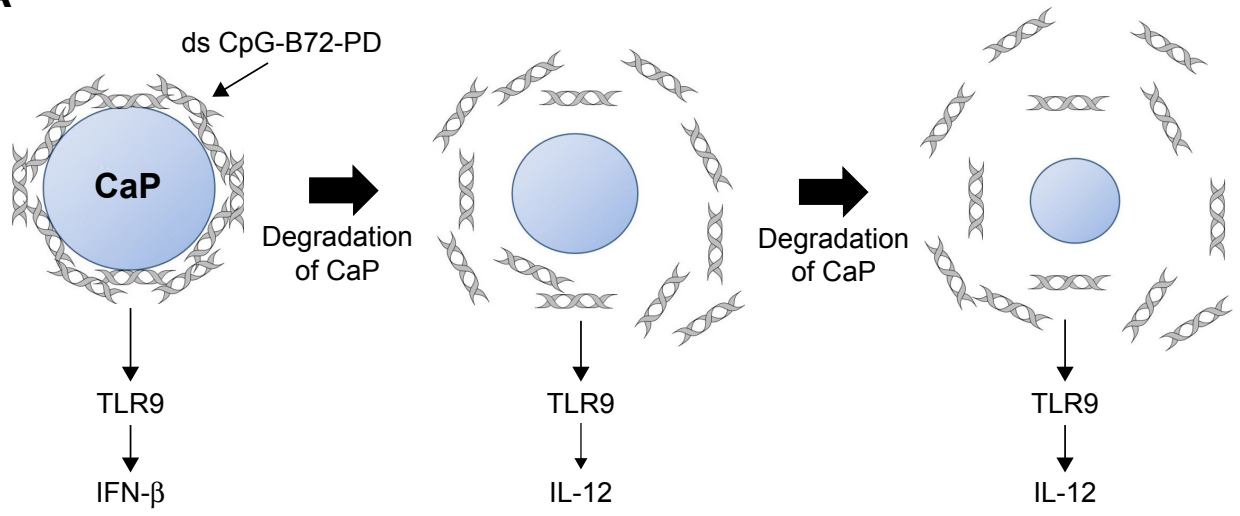

B
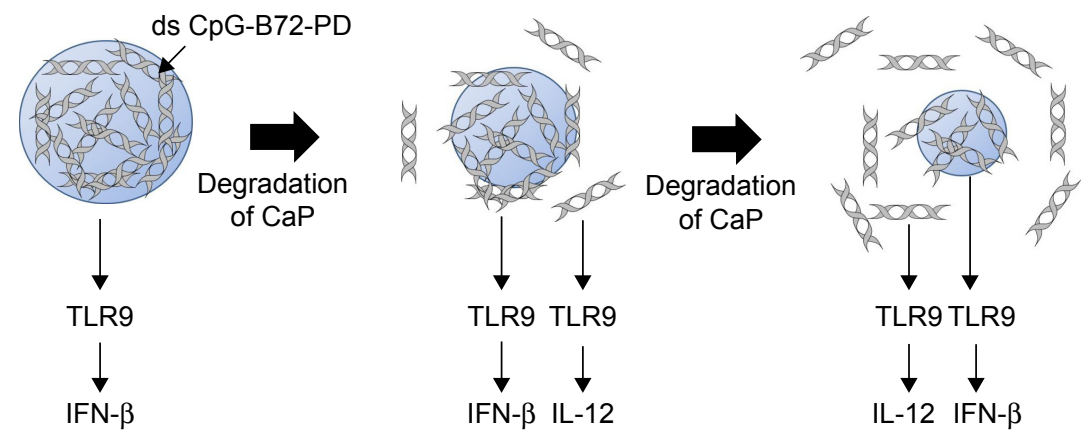

Figure 7 Proposed model of CaP degradation and ODN release.

Notes: (A) ds CpG-B72-PD molecules adsorbed onto the surface of CaP (cross-sectional view of ds CpG-B72-PD-CaP). Most ds CpG-B72-PD molecules are immediately released by the degradation of $\mathrm{CaP}$. (B) ds CpG-B72-PD molecules entrapped by CaP (cross-sectional view of ds CpG-B72-PD/CaP). Surface degradation of CaP releases ds CpG-B72-PD molecules entrapped near the surface, but ds CpG-B72-PD molecules inside CaP are exposed on the new surface.

Abbreviations: CaP, calcium phosphate; ODN, oligodeoxynucleotide; ds, double stranded; CpG-B, class B cytosine-guanine; PD, phosphodiester; TLR, Toll-like receptor; IFN, interferon; IL, interleukin. 
RAW264 cells express cytosolic DNA receptors in addition to TLR9, ${ }^{41}$ including IFN- $\gamma$-inducible protein 16 , dead-box helicase 41, and cyclic GMP-AMP synthase, which recognize ds PD DNA in a sequence-independent manner and induce type-I IFN via stimulator of IFN genes (STING). ${ }^{57-60}$ It is possible that IFN- $\beta$ induction in RAW264 cells stimulated with ds $\mathrm{CpG}-\mathrm{B} 72-\mathrm{PD} / \mathrm{CaP}$ was due to cytosolic DNA receptors, since ds CpG-B72-PD molecules released from $\mathrm{CaP}$ were localized throughout cells including in the cytosol after $4 \mathrm{~h}$ of stimulation with ds CpG-B72-PD/ $\mathrm{CaP}$. However, the degree of IFN- $\beta$ induction by ds $\mathrm{CpG}-$ B72-PD was much higher than that by ds CpG-free72-PD, implying that IFN- $\beta$ induction by ds $\mathrm{CpG}-\mathrm{B} 72-\mathrm{PD} / \mathrm{CaP}$ is heavily dependent on TLR9 but not cytosolic DNA receptors. In L929 and THP-1 cells expressing only cytosolic DNA receptors, ${ }^{41}$ IFN- $\beta$ induction by ds CpG-B72-PD-Lipo was lower than that by B-DNA-Lipo. In addition, both ds CpG-B72-PD/CaP and B-DNA/CaP barely induced IFN- $\beta$ in L929 and THP-1 cells, although ds CpG-B72-PD and B-DNA induced IFN- $\beta$ when complexed with Lipo. Free ds CpG-B72-PD and B-DNA molecules released from $\mathrm{CaP}$ may be degraded before or during escape from endosomes/ lysosomes, while these molecules released from Lipo could still be protected by cationic lipids. However, it is unclear why ds CpG-B72-PD/CaP and B-DNA/CaP barely induced IFN- $\beta$, and there is no information on whether MGN1703 and polypod-like ds PD CpG ODN induce type-I IFN via interaction with cytosolic DNA receptors.

IFN- $\beta$ level in RAW264 cells was higher in the presence of ds CpG-B72-PD/CaP than of ds CpG-B72-PD/Lipo, but there was no difference in the ratio of OVA-specific $\mathrm{CD} 8^{+}$ $\mathrm{T}$ cells to total $\mathrm{CD} 8^{+} \mathrm{T}$ cells in the peripheral blood of mice administered these complexes in conjunction with OVA. This suggests that IFN- $\beta$ induction by ds CpG-B72-PDLipo may be sufficient for activation of cellular immunity. In addition, ds $\mathrm{CpG}-\mathrm{B} 72-\mathrm{PD} / \mathrm{CaP}$ stimulated the production of OVA-specific IgG2a antibody to a greater extent than ds CpG-B72-Lipo. This may be attributed to the high level of IL-12 induction in the presence of ds $\mathrm{CpG}-\mathrm{B} 72-\mathrm{PD} / \mathrm{CaP}$ as compared to ds CpG-B72-PD-Lipo. Although ds CpG-B72PD-Lipo did not increase the ratio of $\operatorname{IgG} 2 \mathrm{a}$ to $\mathrm{IgG1}$, an increase was observed for ds CpG-B72-PD/CaP, implying that the latter can potentially shift the immune response to one that is Th1 predominant. Enhancement of Th1/Th2 balance is a therapeutic strategy for allergies caused by pollen and house dust. ${ }^{61}$ However, we obtained variable results when ds $\mathrm{CpG}-\mathrm{B} 72-\mathrm{PD} / \mathrm{CaP}$ was used as an adjuvant in mice, which could be due to a problem with ds $\mathrm{CpG}-\mathrm{B} 72-\mathrm{PD} / \mathrm{CaP}$ itself such as aggregation and not to individual differences among mice.

In this study, we demonstrated that ds CpG-B72-PD/CaP can activate both cellular and Th1-type humoral immunity. ds CpG-B72-PD/CaP preparation is simple and easily scalable, making it a promising adjuvant for high-coverage vaccines such as influenza vaccine.

\section{Acknowledgments}

We thank Dr Y Shirai and Ms S Matsuura for their technical assistance in animal experiments. We also thank the Transmission Electron Microscope Station and Materials Analysis Station at the National Institute for Materials Science (NIMS) for their technical assistance with SEM and XRD studies. This work was supported by funding from NIMS to NH and a Grant-in-Aid for Scientific Research from the Japan Society for the Promotion of Science and the Ministry of Education, Culture, Sports, Science and Technology (number 16F16356) to NH.

\section{Disclosure}

The authors report no conflicts of interest in this work.

\section{References}

1. Bode C, Zhao G, Steinhagen F, Kinjo T, Klinman DM. CpG DNA as vaccine adjuvant. Expert Rev Vaccines. 2011;10(4):499-511.

2. Fonseca DE, Kline JN. Use of $\mathrm{CpG}$ oligonucleotides in treatment of asthma and allergic disease. Adv Drug Delivery Rev. 2009;61(3): 256-262.

3. Hanagata N. CpG oligodeoxynucleotide nanomedicines for the prophylaxis or treatment of cancers, infectious diseases, and allergies. Int J Nanomedicine. 2017;12:515-531.

4. Shirota H, Klinman DM. Recent progress concerning CpG DNA and its use as a vaccine adjuvant. Expert Rev Vaccines. 2014;13(2):299-312.

5. Brazolot Millan CL, Weeratna R, Krieg AM, Siegrist CA, Davis HL. CpG DNA can induce strong Th1 humoral and cell-mediated immune responses against hepatitis B surface antigen in young mice. Proc Natl Acad Sci US A. 1998;95(26):15553-15558.

6. Chu RS, Targoni OS, Krieg AM, Lehmann PV, Harding CV. CpG oligodeoxynucleotides act as adjuvants that switch on T helper (Th1) immunity. J Exp Med. 1997;186(10):1623-1631.

7. Gürsel M, Verthelyi D, Gürsel I, Ishii KJ, Klinman DM. Differential and competitive activation of human immune cells by distinct classes of CpG oligodeoxynucleotides. J Leukoc Biol. 2002;71(5):813-820.

8. Hemmi H, Takeuchi O, Kawai T, et al. A Toll-like receptor recognizes bacterial DNA. Nature. 2000;408(6813):740-745.

9. Hornung V, Rothenfusser S, Britsch S, et al. Quantitative expression of toll-like receptor 1-10 mRNA in cellular subsets of human peripheral blood mononuclear cells and sensitivity to $\mathrm{CpG}$ oligodeoxynucleotides. J Immunol. 2002;168(9):4531-4537.

10. Takeshita F, Leifer CA, Gursel I, et al. Cutting edge: role of toll-like receptor 9 in CpG DNA-induced activation of human cells. J Immunol. 2001;167(7):3555-3558.

11. Bauer M, Redecke V, Ellwart JW, et al. Bacterial CpG DNA triggers activation and maturation of human $\mathrm{CD} 11 \mathrm{c}^{-}, \mathrm{CD}_{12} 3^{+}$dendritic cells. J Immunol. 2001;166(8):5000-5007.

12. Kadowaki N, Ho S, Antonenko S, et al. Subsets of human dendritic cell precursors express different Toll-like receptors and respond to different microbial antigens. J Exp Med. 2001;194(6):863-869. 
13. Krug A, Towarowski A, Britsch S, et al. Toll-like receptor expression reveals CpG DNA as a unique microbial stimulus for plasmacytoid dendritic cells which synergizes with CD40 ligand to induce high amounts of IL-12. Eur J Immunol. 2001;31(10):3026-3037.

14. Krieg AM. CpG motifs in bacterial DNA and their immune effects. Annu Rev Immunol. 2002;20:709-760.

15. Krug A, Rothenfusser S, Hornung V, et al. Identification of $\mathrm{CpG}$ oligodeoxynucleotide sequences with high induction of IFN-alpha/ beta in plasmacytoid dendritic cells. Eur J Immunol. 2001;31(7): 2154-2163.

16. Verthelyi D, Ishii KJ, Grusel M, Takeshita F, Klinman DM. Human peripheral blood cells differentially recognize and respond to two distinct CpG motifs. J Immunol. 2001;166(4):2372-2377.

17. Hartmann G, Weeratna RD, Ballas ZK, et al. Delineation of a CpG phosphorothioate oligodeoxynucleotide for activating primate immune responses in vitro and in vivo. J Immunol. 2000;164(3): $1617-1624$

18. Hartmann G, Krieg AM. Mechanism and function of a newly identified CpG DNA motif in human primary B cells. J Immunol. 2000;164(2): 944-953.

19. Hartmann G, Battiany J, Poeck H, et al. Rational design of new $\mathrm{CpG}$ oligonucleotides that combine B cell activation with high IFN- $\alpha$ induction in plasmacytoid dendritic cells. Eur J Immunol. 2003;33(6): 1633-1641.

20. Marshall JD, Fearon K, Abbate C, et al. Identification of a novel CpG DNA class and motif that optimally stimulate B cell and plasmacytoid dendritic cell functions. J Leukoc Biol. 2003;73(6):781-792.

21. Samulowitz U, Weber M, Weeratna R, et al. A novel class of immunestimulatory $\mathrm{CpG}$ oligodeoxynucleotides unifies high potency in type I interferon induction with preferred structural properties. Oligonucleotides. 2010;20(2):93-101.

22. Ahonen CL, Doxsee CL, McGurran SM, et al. Combined TLR and CD40 triggering induces potent CD8+ T cell expansion with variable dependence on type I IFN. J Exp Med. 2004;199(6):775-784.

23. Cho HJ, Hayashi T, Datta SK, et al. IFN-alpha beta promote priming of antigen-specific $\mathrm{CD} 8+$ and $\mathrm{CD} 4+\mathrm{T}$ lymphocytes by immunostimulatory DNA-based vaccines. J Immunol. 2002;168(10):4907-4913.

24. Nierkens S, den Brok MH, Garcia Z, et al. Immune adjuvant efficacy of CpG oligonucleotide in cancer treatment is founded specifically upon TLR9 function in plasmacytoid dendritic cells. Cancer Res. 2011;71(20): 6428-6437.

25. Kerkmann M, Costa LT, Richter C, et al. Spontaneous formation of nucleic acid-based nanoparticles is responsible for high interferon-alpha induction by $\mathrm{CpG}-\mathrm{A}$ in plasmacytoid dendritic cells. J Biol Chem. 2005;280(9):8086-8093.

26. Klein DC, Latz E, Espevik T, Stokke BT. Higher order structure of short immunostimulatory oligonucleotides studied by atomic force microscopy. Ultramicroscopy. 2010;110(6):689-693.

27. Puig M, Grajkowski A, Boczowska M, Ausin C, Beaucage L, Verthelyi D. Use of thermolytic protective groups to prevent G-tetrad formation in CpG ODN type D: structural studies and immunomodulatory activity in primates. Nucleic Acids Res. 2006;34(22):6488-6495.

28. Ainalem ML, Campbell RA, Nylander T. Interactions between DNA and poly(amido amine) dendrimers on silica surface. Langmuir. 2010; 26(11):8625-8635.

29. Gungor B, Yagci FC, Tincer G, et al. CpG ODN nanorings induce IFN $\alpha$ from plasmacytoid dendritic cells and demonstrate potent vaccine adjuvant activity. Sci Transl Med. 2014;6(235):235ra61.

30. Hurtado P, Peh CA. LL-37 promotes rapid sensing of CpG oligodeoxynucleotides by B lymphocytes and plasmacytoid dendritic cells. J Immunol. 2010;184(3):1425-1435.

31. Kerkmann M, Lochmann D, Weyemann J, et al. Immunostimulatory properties of $\mathrm{CpG}$-oligonucleotides are enhanced by the use of protamine nanoparticles. Oligonucleotides. 2006;16(4):313-322.

32. Kobiyama K, Aoshi T, Narita H, et al. Nonagonistic Dectin-1 ligand transforms $\mathrm{CpG}$ into a multitask nanoparticulate TLR9 agonist. Proc Natl Acad Sci U S A. 2014;111(8):3086-3091.
33. Agrawal S, Zhao Q, Jiang Z, et al. Toxicologic effects of an oligodeoxynucleotide phosphorothioate and its analogs following intravenous administration in rats. Antisense Nucleic Acid Drug Dev. 1997;7(6):575-584.

34. Bjersing JL, Eriksson K, Tarkowski A, Collins LV. The arthritogenic and immunostimulatory properties of phosphorothioate oligodeoxynucleotides rely on synergy between the activities of the nuclease-resistant backbone and CpG motifs. Inflammation. 2004;28(1):39-51.

35. Brown DA, Kang SH, Gryaznov SM, et al. Effect of phosphorothioate modification of oligodeoxynucleotides on specific protein binding. J Biol Chem. 1994;269(43):26801-26805.

36. Heikenwalder M, Polymenidou M, Junt T, et al. Lymphoid follicle destruction and immunosuppression after repeated CpG oligodeoxynucleotide administration. Nat Med. 2004;10(2):187-192.

37. Henry SP, Novotny W, Leeds J, Auletta C, Kornbrust DJ. Inhibition of coagulation by a phosphorothioate oligonucleotide. Antisense Nucleic Acid Drug Dev. 1997;7(5):503-510.

38. Levin AA. A review of the issues in the pharmacokinetics and toxicology of phosphorothioate antisense oligonucleotides. Biochim Biophys Acta. 1999;1489(1):69-84.

39. Sheehan JP, Lan HC. Phosphorothioate oligonucleotides inhibit the intrinsic tenase complex. Blood. 1998;92(5):1617-1625.

40. Shaw DR, Rustagi PK, Kandimalla ER, Manning AN, Jiang Z, Agrawal S. Effects of synthetic oligonucleotides on human complement and coagulation. Biochem Pharmacol. 1997;53(8):1123-1132.

41. Unterholzner L. The interferon response to intracellular DNA: why so many receptors? Immunobiology. 2013;218(11):1312-1321.

42. Meng W, Yamazaki T, Nishida Y, Hanagata N. Nuclease-resistant immunostimulatory phosphodiester $\mathrm{CpG}$ oligodeoxynucleotides as human Toll-like receptor 9 agonist. BMC Biotechnol. 2011;11:88.

43. Bertran O, del Valle LJ, Revilla-López G, et al. Mineralization of DNA into nanoparticles of hydroxyapatite. Dalton Trans. 2014;43(1): 317-327.

44. Hartmann G, Weiner GJ, Krieg AM. CpG DNA: a potential signal for growth, activation and maturation of human dendritic cells. Proc Natl Acad Sci U S A. 1999;96(16):9305-9310.

45. Napolitani G, Rinaldi A, Bertoni F, Sallusto F, Lanzavecchia A. Selected Toll-like receptor agonist combinations in synergistically trigger a $\mathrm{T}$ helper type I-polarizing program in dendritic cells. Nat Immunol. 2005;6(8):769-776.

46. Roman M, Martin-Orozco E, Goodman JS, et al. Immunostimulatory DNA sequences function as T helper-1 promoting adjuvants. Nat Med. 1997;3(8):849-854

47. Hirsh V, Paz-Ares L, Boyer M, et al. Randomized phase III trial of paclitaxel/carboplatin with or without PF-3512676 (Toll-like receptor 9 agonist) as first-line treatment for advanced non-small-cell lung cancer. J Clin Oncol. 2011;29(19):2667-2674.

48. Manegold C, van Zandwijk N, Szczesna A, et al. A phase III randomized study of gemcitabine and cisplatin with or without PF-3512676 (TLR9 agonist) as first-line treatment of advanced non-small-cell lung cancer. Ann Oncol. 2012;23(1):72-77.

49. Schmidt M, Anton K, Nordhaus C, Junghans C, Witti B, Worm M. Cytokine and Ig-production by $\mathrm{CpG}$-containing sequences with phosphodiester backbone and dumbbell-shape. Allergy. 2006;61(1):56-63.

50. Schmidt M, Hagner N, Marco A, Konig-Merediz SA, Schroff M, Wittig B. Design and structural requirements of the potent and safe TLR-9 agonistic immunomodulator MGN1703. Nucleic Acid Ther. 2015;25(3): 130-140.

51. Weihrauch MR, Richly H, von Bergwelt-Baildon MS, et al. Phase I clinical study of the toll-like receptor 9 agonist MGN1703 in patients with metastatic solid tumors. Eur J Cancer. 2015;51(2):146-156.

52. Um SH, Lee JB, Park N, Kwon SY, Umbach CC, Luo D. Enzyme-catalysed assembly of DNA hydrogel. Nat Mater. 2006;5(10): 797-801.

53. Koo JE, Shin SW, Um SH, Lee JY. X-shaped DNA potentiates therapeutic efficacy in colitis-associated colon cancer through dual activation of TLR9 and inflammasomes. Mol Cancer. 2015;14:104. 
54. Mohri K, Nishikawa M, Takahashi N, et al. Design and development of nanosized DNA assemblies in polypod-like structures as efficient vehicles for immunostimulatory $\mathrm{CpG}$ motifs to immune cells. ACS Nano. 2012;6(7):5931-5940.

55. Nishikawa M, Ogawa K, Umeki Y, et al. Injectable, self-gelling, biodegradable, and immunomodulatory DNA hydrogel for antigen delivery. J Control Release. 2014;180:25-32.

56. Yamamoto S. Electrostatic interaction chromatography process for protein separations: impact of engineering analysis of biorecognition mechanism on process optimization. Chem Eng Technol. 2005;28(11):1387-1393.

57. Ishikawa H, Barber GN. STING is an endoplasmic reticulum adaptor that facilitates innate immune signaling. Nature. 2008;455(7213): 674-678.
58. Ishikawa H, Ma Z, Barber GN. STING regulates intracellular DNAmediated, type-I interferon-dependent innate immunity. Nature. 2009; 461(7265):788-792.

59. Sun W, Li Y, Chen L, et al. ERIS, an endoplasmic reticulum IFN stimulator, activates innate immune signaling through dimerization. Proc Natl Acad Sci U S A. 2009;106(21):8653-8658.

60. Zhong B, Yang Y, Li S, et al. The adaptor protein MITA links virussensing receptors to IRF3 transcription factor activation. Immunity. 2008;29(4):538-550.

61. Joshi VB, Adamcakova-Dodd A, Jing X, et al. Development of a poly (lactic-co-glycolic acid) particle vaccine to protect against house dust mite induced allergy. AAPS J. 2014;16(5):975-985. 


\section{Supplementary materials}

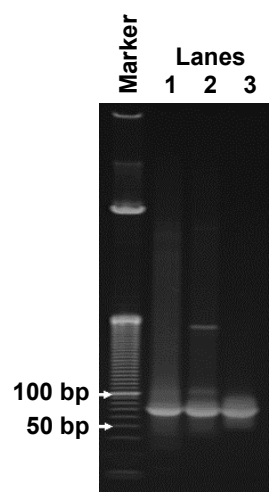

Figure SI Polyacrylamide gel electrophoresis.

Notes: Lane I, ds CpG-B72-PD before purification. Lane 2, ds CPG-B72-PD after purification; ds CpG-B72-PD recovered from the gel was concentrated with $\mathrm{EtOH}$. Lane 3, ds CPG-B72-PD after purification; ds CPG-B72-PD recovered from the gel was concentrated with an ultracentrifugal filter unit.

Abbreviations: ds, double stranded; CpG-B, class B CpG; PD, phosphodiester; CpG, cytosine-guanine; bp, base pairs.

Table SI Primer sequences for the analysis of transcript expression in RAW264.7 and L929 cells

\begin{tabular}{|c|c|c|}
\hline Gene & Forward sequence & Reverse sequence \\
\hline \multirow[t]{2}{*}{ GAPDH } & 5'-GTGGACCTCATGGCC & 5'-TGTGAGGGAGATG \\
\hline & TACAT- $3^{\prime}$ & CTCAGTG-3' \\
\hline \multirow[t]{2}{*}{ IFN- $\beta$} & 5'-GGTCCGAGCAGA & 5'-TCACTACCAGTCCCA \\
\hline & GATCTTCA-3' & GAGTCC-3' \\
\hline \multirow[t]{2}{*}{ IL-I2p40 } & 5'-GAAAGGCTGGGTA & 5'-GGCTGTCCTCAAAC \\
\hline & TCGG-3' & TCAC- $3^{\prime}$ \\
\hline
\end{tabular}

Abbreviations: IFN, interferon; IL, interleukin.

Table S2 Primer sequence for the analysis of transcript expression in THP-I cells

\begin{tabular}{lll}
\hline Gene & Forward sequence & Reverse sequence \\
\hline GAPDH & 5'-CATGGCCTCCAAGGAG $^{\prime}$ & 5'-AGGGGTCTACATGGCA $^{\prime}$ \\
& TAAG-3' & ACTG-3' \\
IFN- $\beta$ I & 5'-TGGGAGGATTCTGCAT $^{\prime}$ & 5'-CAATTGTCCAGTCCCA $^{\prime}$ \\
& TACC-3' & GAGG-3' \\
\hline
\end{tabular}

Abbreviation: IFN, interferon

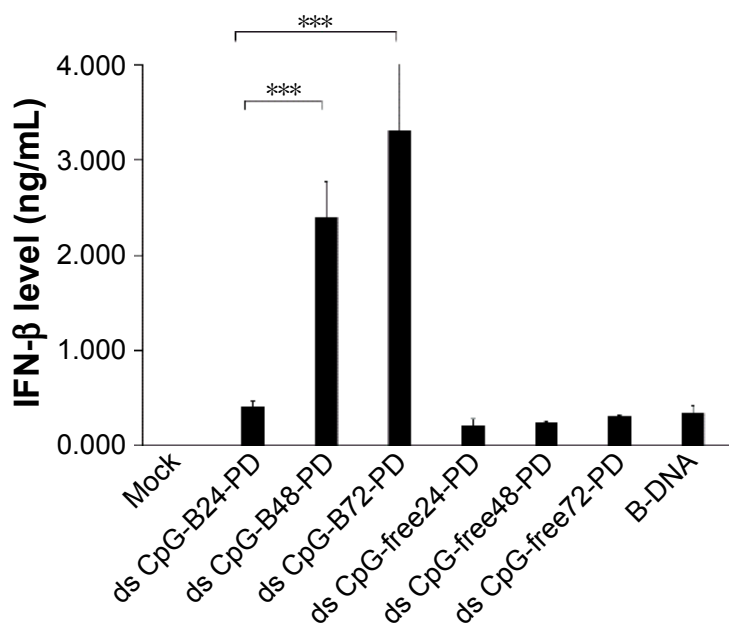

Figure $\mathbf{S 2}$ The level of IFN- $\beta$ secreted into the culture medium.

Notes: IFN- $\beta$ level in the culture medium was determined by ELISA. ds CpG-B-PD ODNs and ds PD CpG-free ODNs were complexed with Lipofectamine 2000. Data represent mean $\pm \operatorname{SD}(n=3)$. $* * * p<0.0125$.

Abbreviations: IFN, interferon; ds, double stranded; PD, phosphodiester; CpG-B, class B CpG; ODNs, oligodeoxynucleotides; CpG, cytosine-guanine.

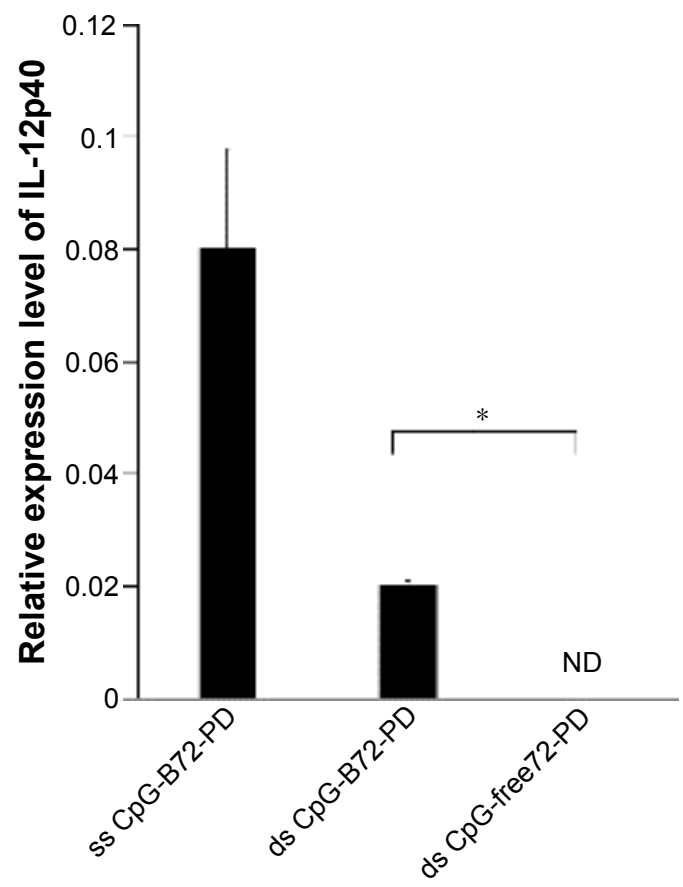

Figure S3 Free ds CpG-B72-PD is a proinflammatory cytokine inducer.

Notes: RAW264.7 cells were stimulated with free ss CPG-B72-PD, ds CpG-B72$\mathrm{PD}$, and ds $\mathrm{C}_{\mathrm{PG}}$-free72-PD. After $6 \mathrm{~h}$, total RNA was recovered, and relative IL- 12 and IFN- $\beta$ transcript levels were evaluated by quantitative real-time PCR. ODN concentration was $50 \mu \mathrm{g} / \mathrm{mL}$. IFN- $\beta$ transcript was not detected in cells stimulated with any ODN. $* p<0.05$.

Abbreviations: $d s$, double stranded; CPG-B, class B CPG; PD, phosphodiester; ss, single stranded; $C_{p}$, cytosine-guanine; IL, interleukin; IFN, interferon; ODN, oligodeoxynucleotide; ND, not detected. 


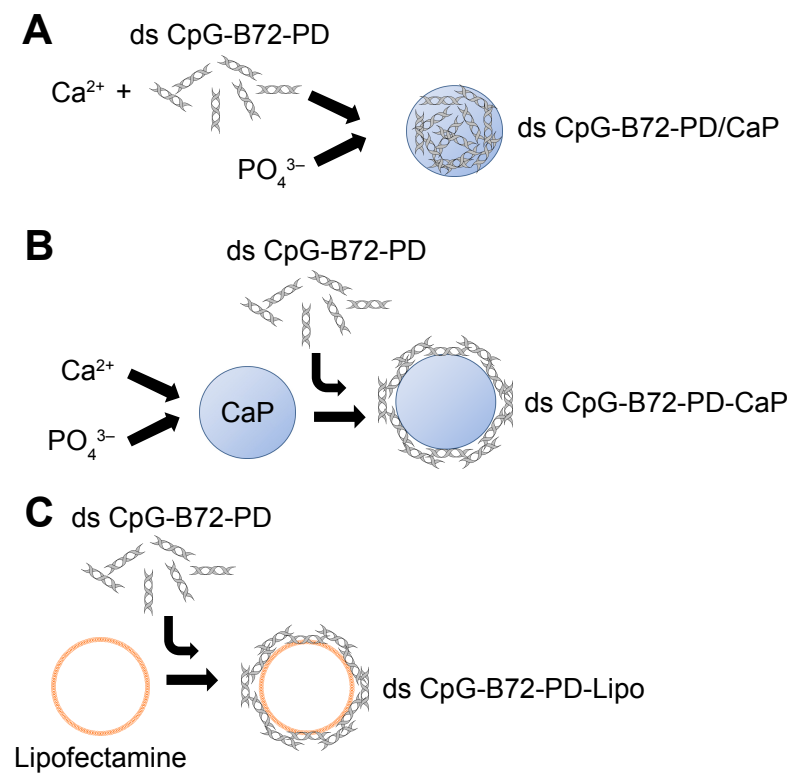

Figure S4 Methods for loading ds CPG-B72-PD onto CaP.

Notes: (A) Entrapment method. ds CPG-B72-PD molecules were entrapped by CaP. (B) Adsorption method. ds CpG-B72-PD molecules were adsorbed onto the surface of CaP. (C) ds CpG-B72-PD complexed with Lipo via electrostatic interactions.

Abbreviations: ds, double stranded; CPG-B, class B CpG; CPG, cytosine-guanine; PD, phosphodiester; CaP, calcium phosphate; Lipo, Lipofectamine 2000.
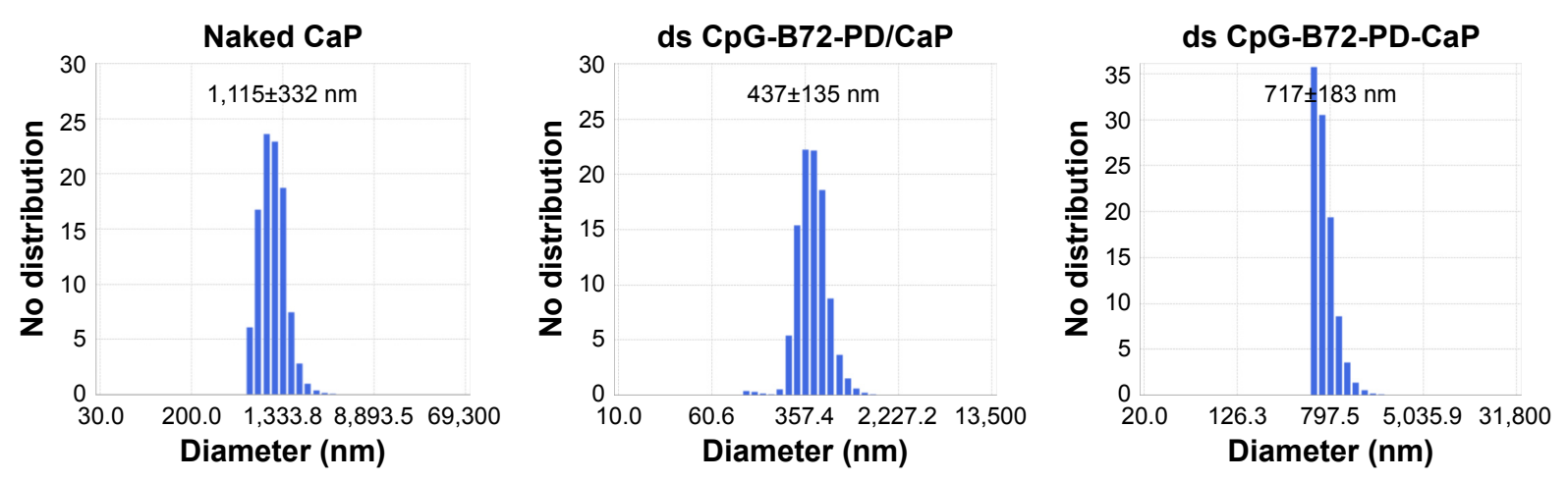

Figure S5 Hydrodynamic size distribution of naked $\mathrm{CaP}$ and ds $\mathrm{C}_{\mathrm{PG}} \mathrm{B}$-B2-PD complexed with $\mathrm{CaP}$.

Notes: Naked CaP, ds CpG-B72-PD/CaP, and ds CpG-B72-PD-CaP were collected by centrifugation at $15,000 \times \mathrm{g}$ for 15 min at $4^{\circ} \mathrm{C}$, and then resuspended in pure water at a concentration of $850 \mu \mathrm{g} \mathrm{CaP} / \mathrm{mL}$. Size distribution was measured at $25^{\circ} \mathrm{C}$ after sonication for I min.

Abbreviations: CaP, calcium phosphate; ds, double stranded; CPG-B, class B CpG; CpG, cytosine-guanine; PD, phosphodiester. 

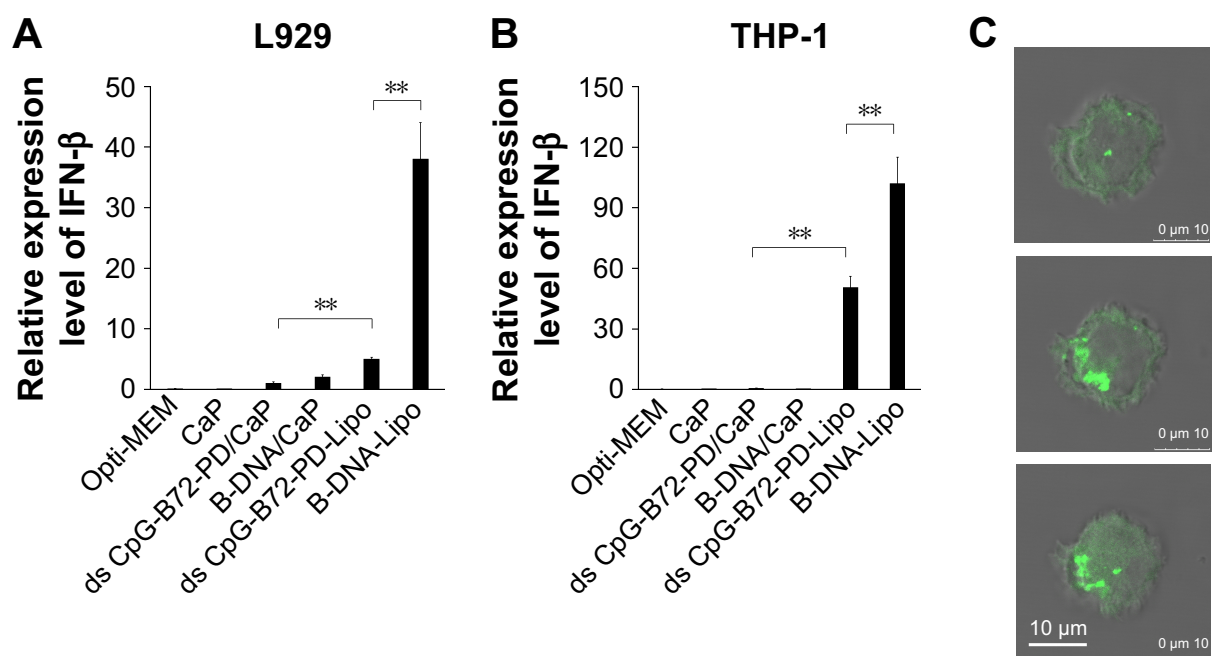

Figure S6 IFN- $\beta$ induction via cytosolic DNA receptors.

Notes: (A) IFN- $\beta$ induction in murine fibrosarcoma L929 cells stimulated for 24 h. (B) IFN- $\beta$ induction in human monocyte-like THP-I cells stimulated for 6 h. ** $p<0.025$. (C) Internalization of FITC-labeled ODNs complexed with CaP by THP-I cells, as observed by confocal fluorescence microscopy. The three images show cross sections of the same cell at different heights.

Abbreviations: IFN, interferon; FITC, fluorescein isothiocyanate; ODNs, oligodeoxynucleotides; CaP, calcium phosphate; ds, double stranded; CpG-B, class B CpG; CpG, cytosine-guanine; PD, phosphodiester; Lipo, Lipofectamine 2000.

A
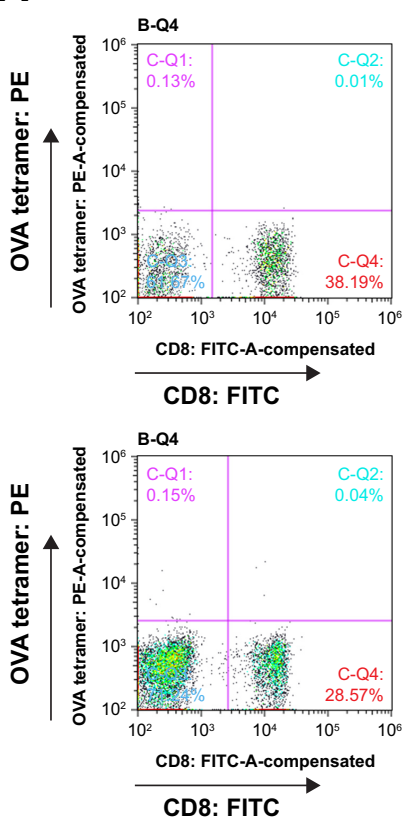

B

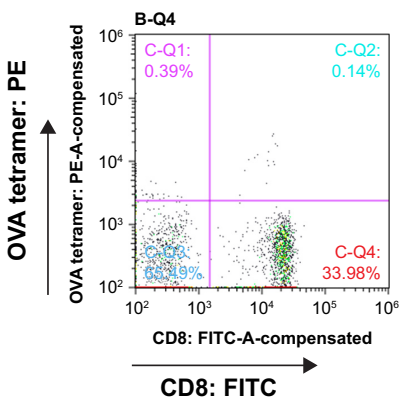

OVA alone
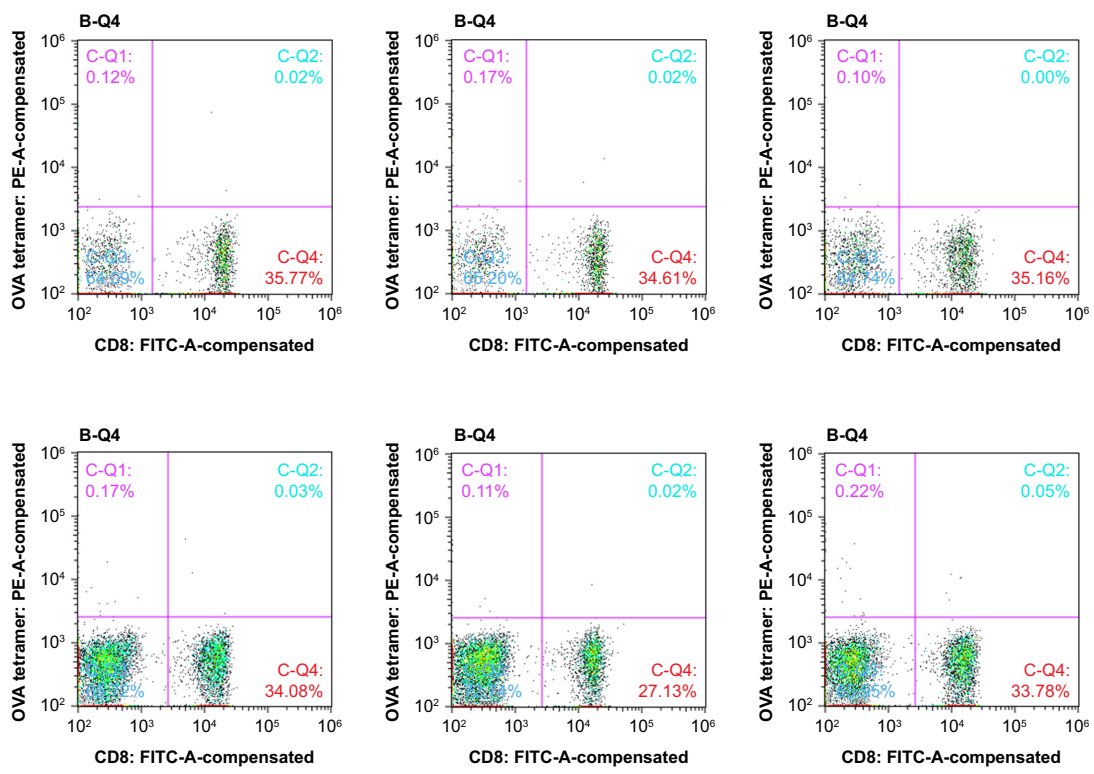
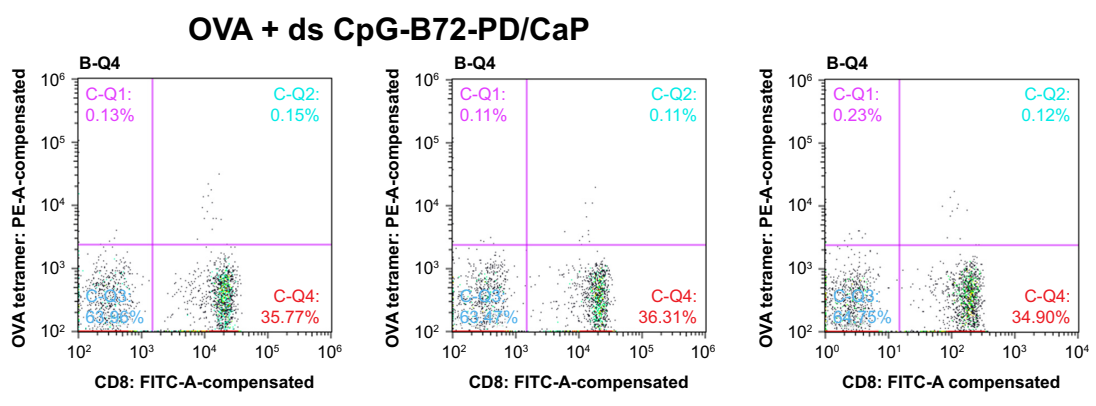

Figure S7 (Continued) 

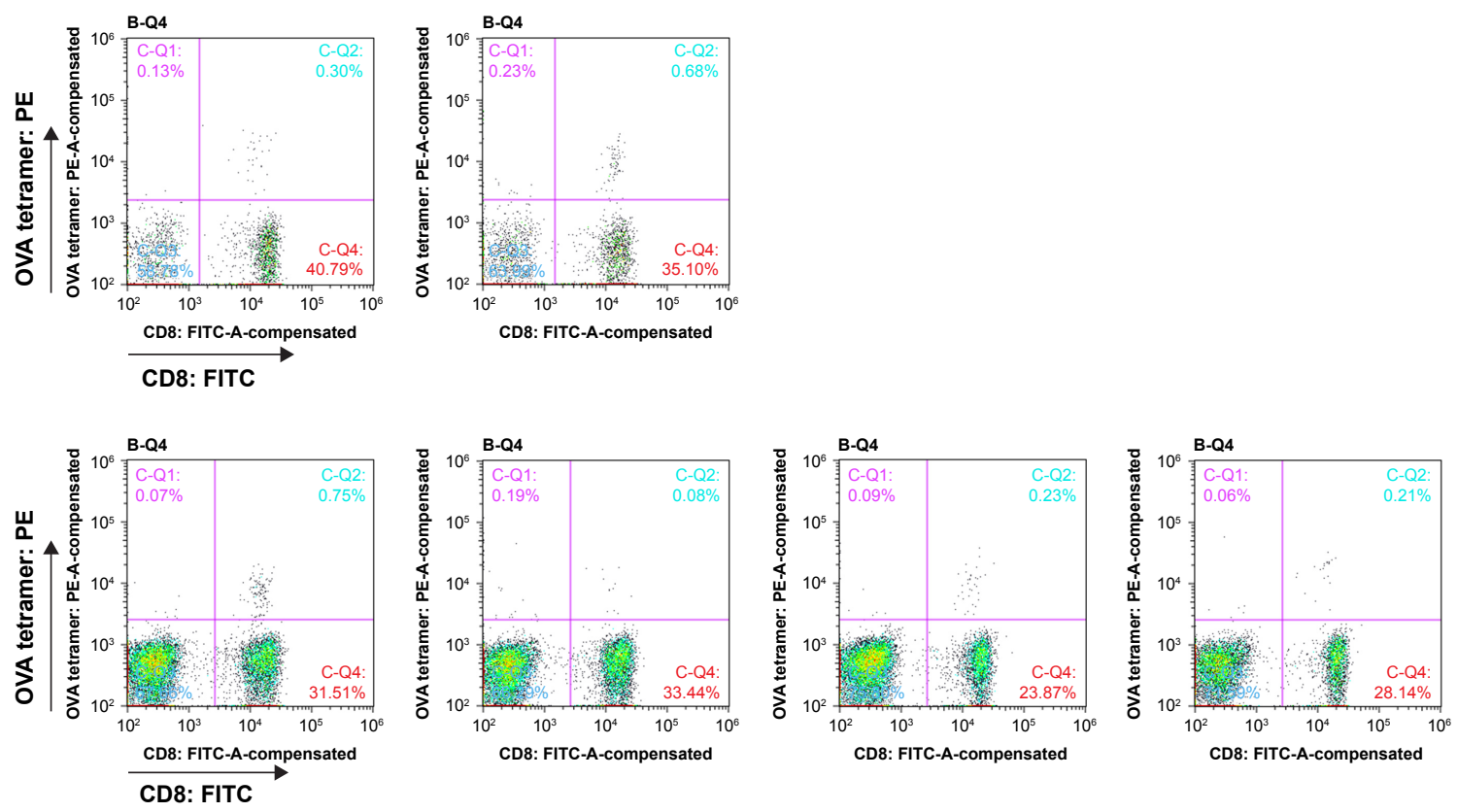

C
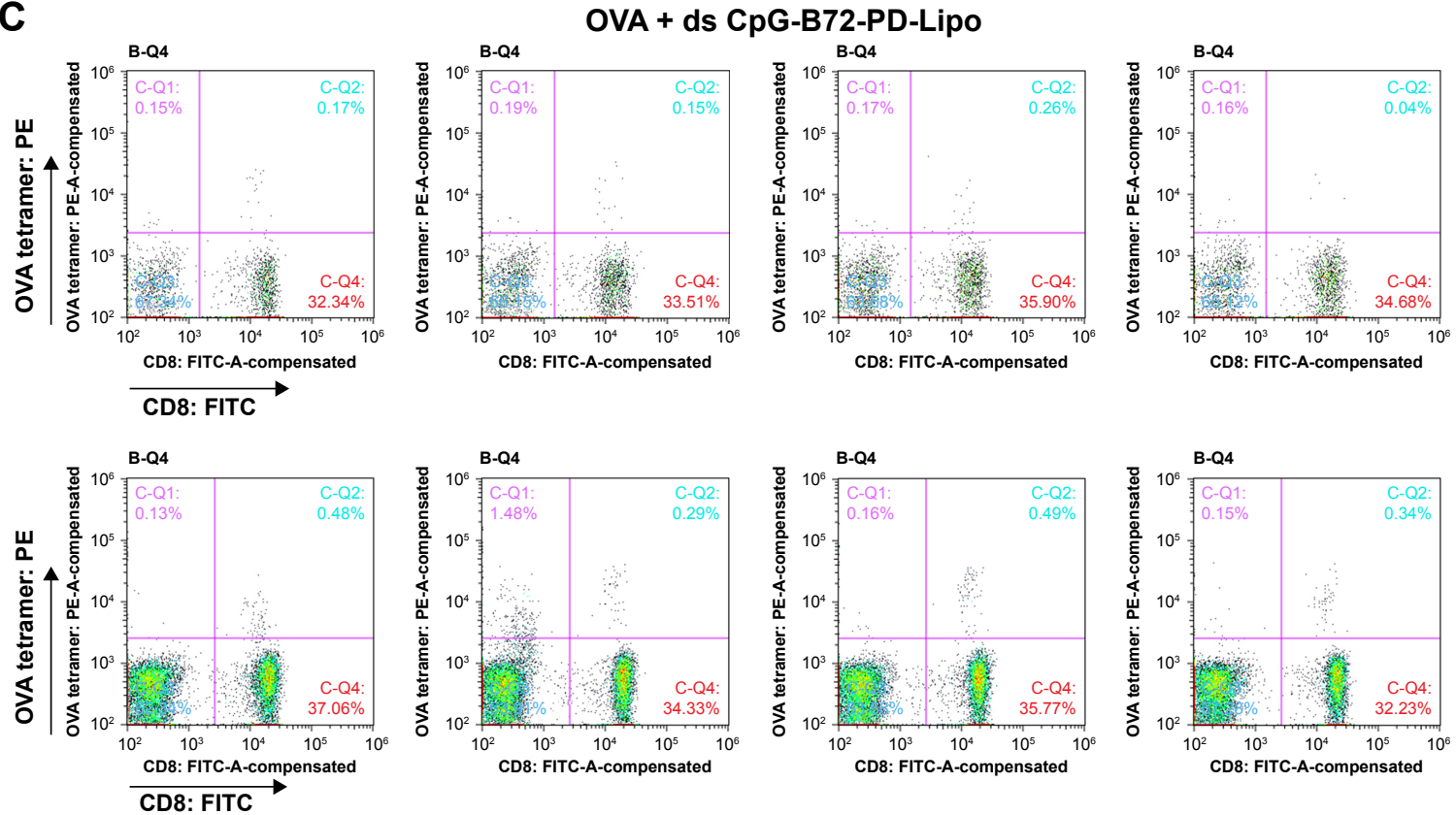

Figure S7 Responses of CD8 ${ }^{+} \mathrm{T}$ cells in peripheral blood analyzed by cell sorting.

Notes: OVA tetramer-vs-CD8 density plot in mouse vaccinated with (A) OVA alone, (B) OVA + ds CpG-B72-PD/CaP, and (C) OVA + ds CpG-B72-PD-Lipo. Ratio of OVA-specific CD8 ${ }^{+} T$ cells to total CD8 ${ }^{+} T$ cells in each mouse was calculated from these density plots. UR (C-Q2) and LR (C-Q4) regions in quadrant region of each density plot indicate the ratios of OVA-specific and OVA-nonspecific CD8 ${ }^{+} \mathrm{T}$ cells in total $\mathrm{CD} 3^{+} \mathrm{T}$ cells. Ratio of OVA-specific CD8 ${ }^{+} \mathrm{T}$ cells was calculated from the equation: $100 \times(\%$ in UR $) /\{(\%$ in UR $)+(\%$ in LR $)\}$.

Abbreviations: OVA, ovalbumin; ds, double stranded; CpG-B, class B cytosine-guanine; PD, phosphodiester; CaP, calcium phosphate; Lipo, Lipofectamine 2000; UR, upper right; LR, lower right; PE, phycoerythrin; FITC, fluorescein isothiocyanate; SSC, side scatter; FSC, forward scatter; Cy5, cyanine 5. 

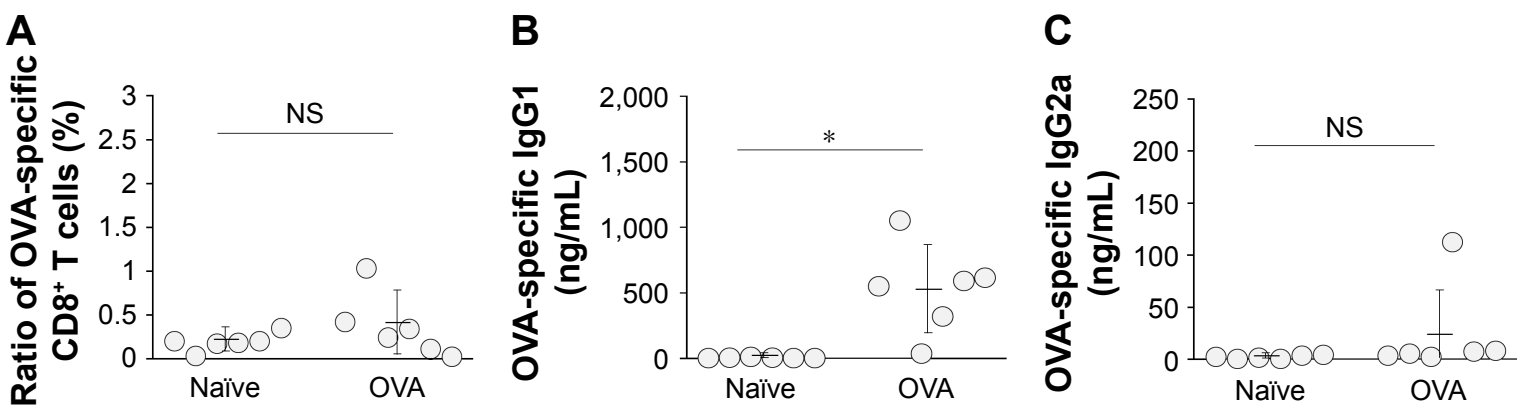

Figure S8 OVA-specific immune responses in mice.

Notes: (A) Ratio of OVA-specific CD8 ${ }^{+} \mathrm{T}$ cells in total CD8 ${ }^{+} \mathrm{T}$ cells in peripheral blood. Each circle corresponds to the ratio of OVA-specific CD8 ${ }^{+} \mathrm{T}$ cells in an individual mouse, and horizontal lines indicate mean \pm SD. (B) OVA-specific IgGI antibody level in serum. Each circle corresponds to OVA-specific lgGI antibody level in an individual mouse. (C) OVA-specific lgG2a antibody level in serum. Each circle corresponds to OVA-specific lgG2a antibody level in an individual mouse. * $p<0.05$ (analysis of variance followed by Tukey's honestly significant difference post hoc test and Ryan's method).

Abbreviations: NS, not significant; OVA, ovalbumin.

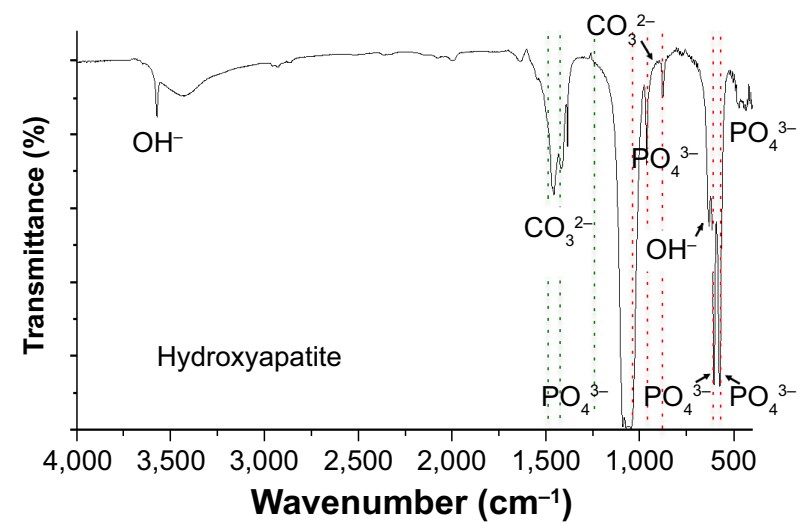

Figure S9 FTIR spectrum of hydroxyapatite.

Abbreviation: FTIR, Fourier transform infrared.

International Journal of Nanomedicine

Dovepress

\section{Publish your work in this journal}

The International Journal of Nanomedicine is an international, peerreviewed journal focusing on the application of nanotechnology in diagnostics, therapeutics, and drug delivery systems throughout the biomedical field. This journal is indexed on PubMed Central, MedLine, CAS, SciSearch ${ }^{\circledR}$, Current Contents ${ }^{\circledR} /$ Clinical Medicine,

Journal Citation Reports/Science Edition, EMBase, Scopus and the Elsevier Bibliographic databases. The manuscript management system is completely online and includes a very quick and fair peer-review system, which is all easy to use. Visit http://www.dovepress.com/ testimonials.php to read real quotes from published authors. 